\title{
Assimilation of surface albedo and vegetation states from satellite observations and their impact on numerical weather prediction
}

Souhail Boussetta $^{(1)}$, Gianpaolo Balsamo $^{(1)}$, Emanuel Dutra $^{(1)}$, Anton Beljaars $^{(1)}$, Clement Albergel $^{(1)}$ 6

${ }^{(1)}$ European Centre for Medium-Range Weather Forecasts, Shinfield Park, Reading, RG29AX, UK

\section{Abstract}

The vegetation state can have a prominent influence on the global energy, water and carbon cycles. This has been particularly evident during extreme conditions in recent years (e.g. Europe 2003 and Russia 2010 heat waves, Horn of Africa 2010 drought, and Australia 2010 drought recovery). Weather parameters are sensitive to the vegetation state and particularly to albedo and Leaf Area Index (LAI) that controls the partitioning of the surface energy fluxes into latent and sensible fluxes, and the development of planetary boundary conditions and clouds.

An optimal interpolation analysis of a satellite-based surface albedo and LAI is performed through the combination of satellite observations and derived climatologies, depending on their associated errors. The final analysis products have smoother temporal evolution than the direct observations, which makes them more appropriate for environmental and numerical weather prediction.

The impact of assimilating these near-real-time (NRT) products within the land surface scheme of the European Centre of Medium-Range Weather Forecasts (ECMWF) is evaluated for anomalous years. It is shown that: (i) the assimilation of these products enables detecting/monitoring extreme climate conditions where the LAI anomaly could reach more than $50 \%$ and in wet years albedo anomaly could reach $10 \%$, (ii) extreme NRT LAI anomalies have a strong impact on the surface fluxes, while for the albedo, which has a smaller inter-annual variability, the impact on surface fluxes is small, (iii) 
neutral to slightly better agreement with in-situ surface soil moisture observations and surface energy and $\mathrm{CO}_{2}$ fluxes from eddy-covariance towers is obtained, and (iv) in forecast using a land-atmosphere coupled system, the assimilation of NRT LAI reduces the near-surface air temperature and humidity errors both in wet and dry cases, while NRT albedo has a small impact, mainly in wet cases (when albedo anomalies are more noticeable).

\section{$1 \quad$ Introduction}

Owing to their influence on the partitioning of energy, mass and momentum fluxes between the land surface and the atmosphere, land surface processes have been shown to substantially impact weather forecasting at short and medium rages (Koster et al., 2010; Beljaars et al., 1996; Rowell \& Blondin, 1990). The impact of land surface processes also extend over different spatial and time scales, and can affect long-term climate projections (Xue et al., 1996; Sellers et al., 1996; Betts et al., 1996; Avissar \& Liu, 1996; Boussetta et al., 2008; Balsamo et al., 2009).

As a fundamental component of a land surface model (LSM), the vegetation layer plays a crucial role in the land-atmosphere exchanges. The vegetation contributes to the evaporation through the plant transpiration and direct evaporation of the plant-intercepted precipitation. In addition, it affects the available surface energy through the radiative transfer within the canopy by modifying the surface albedo (Deardorff 1978).

In most LSMs, the Leaf Area Index (LAI), is used as an indicator of the vegetation state (e.g. greening, mature, senescent, dormant). Traditionally, the LAI was represented through look-up tables dependant on the vegetation type (Viterbo \& Beljaars, 1995). Although its spatial variation was commonly specified according to the biome types, the temporal variation of the LAI was often neglected and sometimes climatological seasonality was introduced together with other major changes. However, the impact of the LAI seasonality could not be assessed (Dorman \& Sellers, 1989; 
these products within LSMs has been tested at different temporal and spatial scales. By using a

satellite-based climatology of LAI within a mesoscale numerical weather prediction (NWP) model, Knote et al. (2009) showed that more realistic LAI information is able to improve the short-range forecast scores of lower-level variables but not their biases. Other studies focused on global circulation models (GCM) and the implications of introducing observed seasonally-varying LAI on the simulations. These studies generally discussed the impact of LAI seasonal (Van den Hurk et al., 2003a; Lawrence \& Slingo, 2004) and inter-annual (Guillevic et al., 2002) variability in terms of annual cycle of the hydrological fluxes. They showed that seasonal LAI can have a non-negligible impact on the seasonality of the surface evaporation and precipitation over land. Recently, Boussetta et al. (2013a) introduced a monthly climatology for LAI based on a MODIS satellite product (Myneni et al., 2002) within the European Centre for Medium-Range Weather Forecast (ECMWF) Integrated Forecasting System (IFS) to replace the fixed maximum LAI previously used. They showed that this results in a reduction of near-surface temperature errors in the tropical and mid-latitude areas, especially during spring and summer seasons. However, the direct impact of the use of near-real-time (NRT) LAI observations on surface fluxes and screen-level variables was not investigated.

In addition, the surface albedo was shown to be one of the important parameters that controls the land surface energy balance and subsequently affects the atmospheric boundary layer through the surface radiative balance (Pielke \& Avissar, 1990). Initially, NWP systems relied on surface albedo derived from soil type and vegetation type maps, neglecting its seasonal and inter-annual variabilities. Preuss and Geleyn (1983) showed that introducing a seasonally-varying satellite-based climatology of surface albedo into the ECMWF IFS has a small impact on medium-range forecasts and a potentially larger impact at longer ranges. While at a regional scale, Berbet and Costa (2003) showed that over Amazonia, most of the spatial and seasonal variability in the simulated climate after a tropical deforestation can be explained by the variability in surface albedo. These previous studies trigger the question whether the use of NRT surface albedo has a significant impact on the near-surface atmosphere in comparison to climatological data. 
Recently, the Copernicus Global Land products (GEOV1) of surface albedo and LAI based on observations from the VEGETATION sensor on board SPOT satellite (Baret et al., 2007; Verger et al., 2011) have become available in NRT with a foreseen operationally-maintained chain. However, the direct use of these products within a NWP system is not possible without quality checks given the spatial and temporal discontinuities they may contain.

In this study, we explore the assimilation of NRT LAI and surface albedo products in a NWP system using optimal interpolation analysis. We evaluate the impact of the NRT analysis products on surface fluxes and surface soil moisture derived from land-only offline simulations of the ECMWF land surface model CHTESSEL (Viterbo \& Beljaars, 1995; Viterbo et al., 1999; Van den Hurk \& Viterbo, 2003b; Balsamo et al., 2009; Dutra et al., 2010; Boussetta et al., 2013a; Balsamo et al., 2011; Boussetta et al., 2013b). The evaluation is then extended to the near-surface air temperature, humidity and precipitation derived from coupled land-atmosphere simulations using the fully-coupled IFS.

\section{The analysis procedure}

The purpose of the analysis is to provide an optimal and complete initial condition to the forecasting system based on available information. Optimal is used here in the sense that different pieces of LAI and Albedo information (climatology, and NRT information) are combined and weighted on the basis of their estimated errors. To obtain such an analysis, the observations are first processed and quality checked, a 10-day climatology is created by averaging over 14 years, and finally the NRT time data is combined with the climatology, to obtain a complete time series. The data products are described in subsection 2.1, the procedure to build the climate is documented in subsection 2.2 and the final analysis procedure is outlined in subsection 2.3.

\subsection{The Copernicus global-land products (GEOV1)}

The GEOV1 LAI and albedo products are based on observations from the VEGETATION sensor on board SPOT satellite. They are produced every 10 days using a composite observation from a 30 days moving window at $1 / 112^{\circ}$ spatial resolution (about $1 \mathrm{~km}$ at the Equator) with a global coverage. Each 
GEOV1 product is provided with its associated error measure $\sigma_{0}$. To take advantage of previous algorithmic experience and existing LAI products, the "best-performing" LAI data (Garrigues et al., 2008) were combined and then used to train a neural network system (Verger et al., 2011). The combined LAI data are the CYCLOPES-V3.1 (Baret et al., 2007) and the collection 5 of MODIS LAI (Myneni et al., 2002). This fusion benefits from the good performance of MODIS LAI for high values and CYCLOPES-V3.1 LAI at low values. After being trained with the fused data, the neural network system is then fed with the atmospherically-corrected reflectances in red, near-infrared, and shortwave-infrared bands from VEGETATION as well as the solar zenith angles and the satellite overpass timing which results into the GEOV1 LAI (Baret et al., 2013).

The GEOV1 surface albedo is also based on observations from the VEGETATION sensor and its derivation follows Geiger and Samain (2004). The method includes cloud screening (Hagolle et al., 2004), atmospheric correction (Rahman \& Dedieu, 1994), directional reflectance normalization (Roujean et al., 1992), and albedo determination for the different integration angles (direct and diffuse) and spectral intervals (visible, near-infrared, and broadband).

Under the Copernicus Global Land framework, the GEOV1 products were validated by analysing their spatial and temporal continuity and consistency as well as their accuracy at the global and regional scales against other global products and the BELMANIP2 sites network (Benchmark Land Multi-site Analysis and Inter-comparison of Products). The conclusion of this validation was that the GEOV1 products are of good quality, show consistent temporal and spatial distributions, and have reasonable accuracy which can meet the requirements for use within LSMs (Camacho et al., 2013).

\subsection{Derivation of Climatological series}

Before processing the climatological product, unreliable retrievals have been discarded from the analysis using the quality flag (QA). In particular: dead detectors, significant clouds and/or snow contaminated pixels, and failure of the radiative transfer model due to problems other than geometry have been filtered out during this pre-processing. Afterwards, the 1-km products were aggregated to 
10-km resolution through a nine-by-nine-point spatial smoothing. The 10-km value is computed when more than $30 \%$ of the $1-\mathrm{km}$ products at the grid point scale have not been flagged and a further snowfree screening is performed on the data. Then a first version of the climatological time series is obtained by averaging data from 1999 to $2012\left(\mathrm{ALB}_{\mathrm{c}} \mathrm{v} 1 / \mathrm{LAI}_{\mathrm{c}} \mathrm{v} 1\right)$.

The first version of the climatological time-series still contains gaps, especially in snow-covered high latitude regions. To overcome this deficiency, a second version of the climatological time series $\left(\mathrm{ALB}_{\mathrm{c}} \mathrm{v} 2 / \mathrm{LAI}_{\mathrm{c}} \mathrm{v} 2\right)$ is generated by spatially filling the data gaps with values from 36 10-daily "selfderived" look-up tables of LAI and albedos for each vegetation type. The look-up tables are derived through stratification of $\mathrm{ALB}_{\mathrm{c}} \mathrm{v} 1 / \mathrm{LAI}_{\mathrm{c}} \mathrm{v} 1$ by vegetation type based on a $90 \%$ vegetation cover threshold for each type. In CHTESSEL, the land use classification follows from the Global Land Cover Characteristics (GLCC) data (Loveland et al., 2000) and use is made of the BiosphereAtmosphere Transfer Scheme (BATS) classification to assign the vegetation types.

Finally, a three-point temporal smoothing is applied to this second version climatological data to obtain a final version $\left(\mathrm{ALB}_{\mathrm{c}} / \mathrm{LAI}_{\mathrm{c}}\right)$. These data are then re-projected and interpolated to a target model simulation grid, together with their associated error $\sigma_{\mathrm{c}}$ in order to be used in the ECMWF model. In this study the target model is run at T511 reduced Gaussian grid horizontal resolution which is about $40 \times 40 \mathrm{~km}$.

\subsection{The optimal interpolation method}

The main objective of data assimilation is to optimize the use of observational data to get the best estimate from all available information. It usually attempts to combine data from different sources in an optimal way to provide the best estimate known as the analysis product. In this study a simple onedimensional data assimilation method is used to produce analyses of albedo and LAI from the GEOV1 data. Following the method of $\mathrm{Gu}$ et al. (2006), two pieces of information are used to generate the analysis product at a given time $t$ (every ten days in this case): the observation $V_{o}$ with its associated error $\sigma_{o}$ and the climatological values $V_{c}$ with their associated errors $\sigma_{c}$ ( $V$ being the 


$$
J\left(V_{a}\right)=\left[\frac{V_{a}-V_{o}}{\sigma_{o}}\right]^{2}+\left[\frac{V_{a}-V_{c}}{\sigma_{c}}\right]^{2}
$$

$$
\sigma_{c}^{2}=\frac{\sigma_{c p}^{2}+\sigma_{c o}^{2}}{2} \text {, where }
$$$$
\sigma_{c p}^{2}=\frac{1}{N} \sum\left[V_{o s}-V_{c}\right]^{2} \text { and } \sigma_{c o}^{2}=\frac{1}{N} \sum\left[\sigma_{o}\right]^{2}
$$

$165 N$ is the number of observations and $V_{o s}$ is the observation value after the first smoothing process. For the few points where either the observation error is zero or the observation is equal to the

167 climatological value, a $10 \%$ error is then adopted. Although this procedure attempts to reasonably characterise the climatological error statistics, it may still hold some caveats given the lack of ground 
truth information at this temporal and spatial scale. For instance the errors coming at each step of the climatology derivation procedure are summarised in one metric $\left(\sigma_{c p}^{2}\right)$, and the simple average between the climatological average variance $\sigma_{c o}^{2}$ and the climatological processing variance $\sigma_{c p}^{2}$ assume an equal contribution between these two components.

To avoid a rough replacement with the climatological data in the case of missing observation and relax non-realistic jumps, a further processing is performed by adding the climatological tendency to the last analysis value assuming the analysis tendency is similar to the climatological one:

$\frac{V_{a}(t)-V_{a}(t-1)}{\Delta t}=\frac{V_{c}(t)-V_{c}(t-1)}{\Delta t}$

To summarize, a flowchart of the data processing and analysis procedure is illustrated in Figure 1.

\section{Methods to evaluate the impact of near real time albedo and LAI}

The impact of the assimilation of NRT LAI and albedo is evaluated by focusing on extreme events.

We examine the surface fluxes and surface soil moisture derived from CHTESSEL offline simulation as well as on the near-surface air temperature and humidity derived from coupled forecast simulations using the ECMWF IFS. The evaluation is performed by comparing against control simulations based on climatological LAI and albedo. The surface fluxes are also evaluated against available FLUXNET eddy-covariance network (Baldocchi et al., 2001; Baldocchi et al., 2008) and the Boreal Ecosystem Research and Monitoring Sites (BERMS, Betts et al., 2006) data for 2003 as no flux data was available to us in 2010, while the surface soil moisture are evaluated against 2010 data from the International Soil Moisture Network (ISMN, Dorigo et al., 2011; http://ismn.geo.tuwien.ac.at/). The evaluation procedure is illustrated in Figure 2. 


\subsection{Offline simulations}

190 The offline (or stand-alone) simulations offer a computationally-efficient and controlled framework

191 for studying the benefits and deficiencies of a given land surface parameterization without having to

192 consider complex surface/atmosphere interactions as present in coupled mode.

The offline simulations are performed at the global scale for the period covering the GEOV1 data (1999 to 2012). However, the results are focused on 2010 because it contains contrasting extreme events in the Horn of Africa and Australia. All the land simulations are forced with 3-hourly meteorological data extracted from the ECMWF ERA-Interim (ERA-I) reanalysis (Dee et al., 2011). These forcing data originally produced on a T255 reduced Gaussian grid are spatially interpolated to a T511 grid corresponding to a resolution of about $40 \mathrm{~km}$. The temperature, surface pressure, humidity and wind fields are instantaneous values and representative of the lowest level in the atmospheric model that is at $10 \mathrm{~m}$ above the surface. The incoming surface radiation (in its long- and short-wave components), rainfall and snowfall are provided as 3-hourly accumulations. The instantaneous fields are linearly interpolated in time to the 30 minutes time-step of the land surface model. They are from the 3-, 6-, 9- and 12-hour forecasts starting from the daily analyses at 00 and 12 UTC. As a compromise between spin-up effects (mainly in radiation) and forecast errors, the fluxes are averages from the 3-hourly forecast intervals $9-12,12-15,15-18$ and $18-21$ hours starting from the daily analyses at 00 and 12 UTC (see Kallberg, 2011 for a discussion on the spin-up characteristics of ERA-I). Fluxes and instantaneous fields are matched by verification time. Precipitation is kept constant over the 3-hourly interval, long-wave downward radiation is linearly interpolated and downward solar radiation is disaggregated in time making use of the solar angle, but conserving the 3hourly integral. The land-use information is derived from the GLCC data set (Loveland et al., 2000) at

211 the same resolution as the forcing data.

212 Four global offline model integration experiments are performed: 
213 i. A control run where the GEOV1 LAI and albedo climatological products are used to force the

214 CHTESSEL model (SCLIM).

215 ii. An experiment run where CHTESSEL is constrained using the analysis products of GEOV1 NRT

216 LAI and albedo (SNRT).

217 iii. An experiment run where CHTESSEL is constrained using the analysis products of GEOV1 NRT

218 LAI and albedo data is from climatology (SLAINRT).

219 iv. An experiment run where CHTESSEL is constrained using the analysis products of GEOV1 NRT

220 albedo and LAI data is from climatology (SALBNRT).

221 The different experiment configurations are summarized in Table 1. In this study, as prognostic vegetation evolution is not used in CHTESSEL, the assimilation of NRT LAI and albedo refers to a direct insertion of the analysed product given that a model background component is not present.

The comparison between these experiments allows the evaluation of the impact of using the NRT LAI and albedo with reference to the use of climatology. To be able to detect such an impact, focus is mainly on extreme anomalous year. In this case 2010 was chosen because it holds two known contrasting events: a drought in the Horn of Africa and a wet period in Australia.

\subsection{Forecast experiments}

230 To evaluate the impact of the assimilation of NRT LAI and albedo on the surface-atmosphere 231 interaction, a series of 3-day forecasts initialised every day from 1 January 2010 00UTC to 31 232 December 2010 00UTC was performed using the different LAI and albedo products. The ECMWF 233 IFS which includes CHTESSEL was used for these forecasts simulations. Given the different time scales between land surface processes and atmosphere, and to avoid spin-up problems related to slow surface processes, the surface initial conditions of each forecast experiments are obtained from the 
corresponding surface offline simulations. The focus is on short-range forecasts which have the

237 advantage that the synoptic situation is in the predictable range. Still, changes in albedo and LAI

238 would have an impact on near-surface atmosphere through radiative forcing and sensible and latent

239 heat flux. Screen-level temperature and moisture can be verified using the analysis, which draws

240 closely to the surface synoptic observations. The model is run with 137 vertical levels at T511 $(\sim 40$

$241 \mathrm{~km}$ ) horizontal resolution. The experiments configurations are summarized in Table 1.

242 The assessment of the NRT impact is done for the screen-level temperature and relative humidity

243 through two metrics named hereafter sensitivity and impact:

Where subscripts $c t l$ refers to climatological LAI/albedo based forecast, exp refers to NRT

$\mathrm{LAI} /$ albedo based forecast and "an" refer to the operational analysis. The equivalent quantities are computed for relative humidity. Therefore a positive (negative) sensitivity would mean an increase (decrease) of temperature/relative humidity at the 2-m level due to assimilation of the NRT data. A positive (negative) value of the impact means an increase (reduction) of the 2-m temperature/relative humidity error in comparison to the operational analysis due to the use of the NRT analysis.

\section{Results of the analysis procedure}

\section{$253 \quad$ 4.1 Characterisation of the analysis products}

254 Using the above-described system (Figure 1), GEOV1 LAI and albedo are assimilated over the 19992012 period. Figure 3 presents maps of the analysed LAI (right column)) and their differences from the observation (left column) for dates representative of the four seasons of year 2006 (25 January, 25 April, 25 July and 25 October). The analysis product shows a realistic seasonal evolution and a smooth spatial distribution generally consistent with the vegetation types (Figure $3 \mathrm{e}, \mathrm{f}, \mathrm{g}$ and $\mathrm{h}$ ). The main spatial features of the LAI on a global scale generally agree with other standard products (as in 
Fang et al., 2012 and 2013). The signatures of the African tropical forest, the Amazon area and the

261 European and American Boreal forest, as well as the signature of crop areas like in central Europe and western USA, are correctly captured. Nevertheless, the magnitude and the spatial extent of these signatures can vary significantly depending on regions and seasons. The crops and grass regions show pronounced seasonal cycles with LAI varying between 0.2 and $2.7\left[\mathrm{~m}^{2} \mathrm{~m}^{-2}\right]$, while the boreal forest shows smaller seasonal amplitude for the evergreen needle-leaf from 1.2 to $4.2\left[\mathrm{~m}^{2} \mathrm{~m}^{-2}\right]$ and higher variation from 0.8 to $4.0\left[\mathrm{~m}^{2} \mathrm{~m}^{-2}\right]$ for the deciduous needle-leaf. The tropical forests have a very mild seasonal cycle with an average amplitude of $0.3\left[\mathrm{~m}^{2} \mathrm{~m}^{-2}\right]$.

The left column of Figure 3 shows that the differences between analyses and observation data can be quite large at high latitudes where the original products are most affected by snow and $\sigma_{o}$ is large. This is particularly visible in winter, spring and late autumn (Figure 3a, b, d). On the other hand, the summer season shows the least differences, especially in high latitudes where problems from snow contamination are minimal and $\sigma_{o}$ is much smaller (Figure 3c). Also in the tropical regions the difference with the assimilated LAI suggests a higher weight of the climatology mainly caused by the cloud contamination of the observed data. At the high latitudes $\left(>70^{\circ} \mathrm{N}\right)$, the positive correction in the Siberian tundra with a smooth transition toward the other regions shows the effectiveness of the extracted look-up tables in filling gaps, even in a region with no observations (Figure 3c). This suggests that the analysed LAI has indeed benefited from the processing chain and led to a superior data usable for environmental applications.

Considering the albedo product, similarly to Figure 3, Figure 4 shows the analysis of snow-free broadband diffuse albedo and its difference from the observed data for dates representing the four seasons of year 2006 (25 January, 25 April 25, 25 July and 25 October). As expected from such data, the desert areas show very small seasonal and spatial variations, while the other regions show a spatial distribution similar to the MODIS data (Gao et al., 2005). In terms of seasonal variation, the analysis product shows a consistent response to vegetation that is seasonality associated with the background 
bare soil exposure (Figure 4e, f, g and h). The European boreal forest, for instance, displays a consistent albedo evolution related to the forest growth seasonality. Similarly, the deciduous broadleaf forest albedo in the southern area of the tropics displays an evolution consistent with the LAI analysis maps (Figure 3). The signal from low vegetation regions shows a less obvious pattern as the background bare soil can play a stronger compensating role in the albedo value. However, these types generally display an increase of the albedo toward the summer, especially over grass and crop areas; even when the soil background is more exposed, it displays a brighter albedo linked to a soil moisture decrease.

Figure $4 a, b, c$ and $d$ shows that in general the differences between the analysed and the observed albedo are more homogeneous than the LAI ones: this is mainly due to the small variability of the broadband albedo compared to LAI in characterizing the land use. The highest differences are associated with high observation errors over snow covered areas and a large illumination angle of high latitudes. This is particularly seen in spring and winter when the analysis draws more closely to the climatology. The lowest differences occur in the summer months (Figure 4c) when snow is absent and the observation have more weight. However, the analysed albedo tends to have higher differences with that observed in cloud contaminated area as it is the case for the Indian peninsula and the WestAfrican monsoon region.

\subsection{Inter-annual variability and anomalies in the analysis products}

303 Given that the focus of this study is also to check the impact of the assimilated NRT products on the surface fluxes and the near-surface atmospheric variables, a pre-assessment of the difference between the NRT analysis products and their respective own climatologies is necessary. For the sake of completeness and to be able to only extract the NRT effect, new 10-daily climatological data are generated by averaging the analysis products through the whole 1999-2012 period. The result is slightly different from the climatology used in the data assimilation because of the use of error estimates. In the remainder of this paper, reference to climatology is associated to this new product. 
310 Figure 5 displays the relative anomaly $\left(\frac{100 *(N R T-C L I M)}{C L I M}\right)$ of the analysed LAI (left panel) and 311 analysed albedo (right panel) with regard to their 1999-2012 climatologies for three known extreme 312 event cases: the 2003 European drought (upper panel), the 2010 Russian summer heat wave (middle 313 panel) and the 2010 Horn of Africa drought which occurred at the same period as a drought recovery 314 in Australia (lower panel). Figure 5 shows that for these cases, the LAI anomaly is generally more pronounced than the albedo anomaly. The LAI anomaly can reach $80 \%$ of the climatological values, whereas the albedo anomaly does not exceed 20\%. In addition, the albedo anomaly is more pronounced in extreme wet cases such as in central Australia during the wet period of November 2010 where the anomaly reached $-10 \%$, while LAI anomaly is perceptible in both dry and wet cases (e.g. the anomaly during the Horn of Africa drought reached $-40 \%$ and the anomaly over the central Australia attained $+40 \%$ of the climatological values). Owing to the soil background exposure compensation which also depends on the soil type and moisture, the link between LAI anomaly and albedo anomaly is not always clear. However Figure 5 shows that a positive LAI anomaly is generally associated with a negative albedo anomaly in low vegetation areas. $20 \%$ to $40 \%$ LAI positive anomaly correspond to a $1 \%$ to $10 \%$ negative albedo anomaly depending on the low vegetation type and cover.

The inter-annual variation of the analysis LAI and albedo is depicted in Figure 6 by time series over the regions where extreme events occurred in 2010 (central Australi, Horn of Africa and Russia). The variability over Russia is smaller than that of the Horn of Africa or central Australia. This suggests that the inter-annual variability of LAI and albedo are more pronounced over regions with low vegetation. In addition, in terms of absolute value, the inter-annual variability of LAI is larger than the variability of albedo. For instance, over the Horn of Africa the difference between the LAI of November 2006 and November 2010 is more than 100\%. It is also the case between October 2002 and October 2010 over central Australia. However the albedo variability does not exceed $10 \%$ over those regions. 
Focusing on the 2010 extremes events, during the July 2010 Russian heat waves, the LAI was lower than the 10th percentile of the whole 1999-2012 period, while the albedo was between the 70th and 90th percentile. In the case of the Horn of Africa drought (November 2010), the LAI was much lower than the 10th percentile whereas the albedo was higher than the 90th percentile. While in the case of the drought recovery over Australia during the same period, the LAI of central Australia was at its maximum and much higher than the 90th percentile and the albedo reached its 10th percentile. This almost direct opposite relation between LAI and albedo in terms of percentiles is not translated in absolute anomalies because LAI variability is higher than the albedo one.

The above results confirm that with the assimilation system, the GEOV1 NRT LAI and albedo have smooth and realistic fields that are capable of mimicking their inter-annual variability and correctly detect and monitor extreme events.

\section{$5 \quad$ Impact on fluxes and atmospheric forecasts}

\section{$347 \quad 5.1 \quad$ Surface stand-alone simulations}

\subsubsection{Impact on $\mathrm{CO}_{2}$ fluxes}

Figure 7 shows November 2010 global Net Ecosystem Exchange (NEE) difference between the experiment SNRT where the model is constrained by NRT LAI and albedo, and the control run SCLIM based on the climatological GEOV1 LAI and albedo. November 2010 is characterized by a drought in the Horn of Africa and a wet event corresponding to drought recovery in central and eastern Australia as identified in the previous section (Figures 5 and 6). In the Horn of Africa, the run with climatological data (Figure 7a) shows that in November the region is under a respiration regime (By model convention downward fluxes are positive, so respiration is negative), and the difference plot (Figure 7c, b, d) show an anomaly that reaches more than 50\%. These are differences (anomaly) of the absolute fluxes and therefore, positive indicates an increase and negative indicates a decrease of the flux independent of its direction. These results suggest that the respiration increase is mainly due to the decrease in LAI (Figure 7b, c), as the difference with the simulation using only NRT albedo 
360 (SALBNRT) is not significant (Figure 7d). This anomaly is well above the 90th percentile of the 361 whole 14 years period (1999-2012) considered in this study (Figure 8, left) which is consistent with 362 the LAI negative anomaly (Figure 6).

363 For the Australia wet case, the results from the SCLIM experiment show an overall respiration regime and a localized photosynthesis regime at the east to southeast region. The difference with the SNRT experiment shows a decrease in respiration and an increase in photosynthesis both explained by the co-located LAI positive anomaly (as seen on Figure 5). The NEE anomaly in this case also reached more than 50\%, and the anomaly for the central part of Australia (Figure 8, right) was less than the 10th percentile corresponding to the LAI anomaly which exceeded the 90th percentile for the same region (Figure 6). The NRT albedo analysis impact (SALBNRT experiment) shows a very small increase in the respiration although its anomaly was at the 10th percentile level (Figure 6).

\subsubsection{Impact on the energy fluxes}

Similar to the $\mathrm{CO}_{2}$ flux, the energy fluxes for November 2010 were also affected by the LAI and albedo anomaly detected in the GEOV1 NRT analysis product. As a consequence to the observed decrease of LAI over the Horn of Africa, a decrease in the Latent heat flux (Figure 9b, c) and an increase in the sensible heat flux (Figure 10b, c) were obtained by the model for both SLAINRT and SNRT configurations. The experiment using only the albedo NRT analysis (SALBNRT) shows a minor decrease in both latent and sensible heat fluxes related to a mild increase of the surface albedo (Figure 6b) which induces a decrease in the net surface radiation. In this case, the increase of the surface albedo is due to the brightening of the surface caused by the drought condition. However, when combined, the NRT LAI and albedo (SNRT), the resultant anomaly signal of both latent (Figure 9b) and sensible heat fluxes (Figure 10b) is mainly driven by the LAI anomaly. anomaly in both SNRT and SLAINRT configurations resulted in an increase of the latent heat flux and a decrease of the sensible heat flux, especially over the densely vegetated area in the eastern 
region. In the central Australia region which is less vegetated, the wet condition led to a decrease of the surface albedo resulting in an increase of the sensible heat flux (SALBNRT and SNRT). This effect was more important than the decrease caused by the LAI anomaly (SLAINRT) due to the small vegetation cover in this region as depicted in (Figure 10).

\subsubsection{Comparison with in-situ observations}

Given the lack of in-situ data over the considered areas for November 2010, an accurate quantitative assessment of the simulated flux differences is not possible. However, a general assessment of the NRT LAI and albedo is performed with the available flux and soil moisture observations using 52 FLUXNET sites in 2003 and 523 sites from the ISMN in 2010. The later belongs to 8 networks located over contrasting biomes and climate conditions.

Table 2 shows the benchmarking metrics of the model simulations against FLUXNET observations averaged over 52 sites for 2003. In this case, the observation sites were mainly located in Europe and North America. Slightly better agreement with in-situ surface energy and $\mathrm{CO}_{2}$ fluxes is obtained when NRT data is used, although the magnitude of the improvement is quite small and in some cases may not be within the significance range. For the energy fluxes, the use of the NRT data reduces the latent heat fluxes bias for $69 \%$ of the sites used in this comparison. In the case of the sensible heat fluxes, using LAI NRT and albedo NRT reduces the bias for $67 \%$ of the sites while when using LAI NRT and albedo climatology the bias is reduced for $75 \%$ of the sites. The different simulation results have an equal average correlation over the 52 sites $(0.85$ for the latent heat flux, 0.74 for the sensible heat flux and 0.82 for the $\mathrm{CO}_{2}$ flux). However, in terms of the number of sites with improved metrics, the correlation of the gross primary production increased for $57 \%$ of the sites when using NRT LAI and albedo and for $63 \%$ of the sites when NRT LAI and albedo climatology are used. The comparison between SNRT and SLAINRT related to the use of both NRT LAI and albedo or only LAI NRT respectively suggests that the LAI NRT signal is in general dominant although the albedo NRT tends to reduce the sensible heat flux bias as albedo has a direct impact on this variable. 
411 Similarly for the soil moisture benchmarking (Table 3), the signal of the improvement owing to the 412 assimilation of NRT LAI and albedo is quite small although more than $50 \%$ of the modelled sites 413 experienced a minor improvement in their correlation with the observed soil moisture. This signal is 414 equally valid for the surface which is evaluated against 523 sites of the ISMN and for the root-zone 415 for which the evaluation is only performed on 58 sites of the USCRN network (Bell et al., 2013) 416 given the availability of observations.

417 In addition, it is important to note that the metrics shown represent an average for all the sites 418 considered for a full year. Therefore, the impact of any inter-annual variability or anomaly signal that 419 NRT data may hold in some sites will be diluted with sites having a "climatological" year behaviour. 420 However, at the regional and global scales, an indirect assessment would be feasible by meteorologically evaluating the LAI and albedo NRT analysis impact on near-surface temperature and humidity and precipitation forecasts.

\subsection{Impact on Forecast experiments}

Figures 11 shows the results of the forecast experiment using the LAI NRT analysis (FLAINRT) for the global land for the 36-hour forecast (valid at 12 UTC) in comparison to the control run FCLIM related to the use of LAI climatology for November 2010. The use of NRT LAI results in a neutral to positive impact for the global 2-m temperature (Figure 11c). In this case, the bias reduction corresponds to a temperature change that reaches $2 \mathrm{~K}$ caused by the LAI anomaly, with a warming over the Horn of Africa co-located with the LAI reduction and a cooling co-located with the LAI positive anomaly over eastern Australia (Figure 11a). The African tropics also experiences a cooling partially related to a positive LAI anomaly which contributes in reducing the temperature bias in comparison with the operational analysis. However a similar cooling over the Indian peninsula results 
in a mild bias increase of $0.2 \mathrm{~K}$. The relative humidity results show similar patterns. The regions which have a temperature increase display a drying in the relative humidity, while the regions that have a cooling show a moistening in the relative humidity (Figure 11b). As for the temperature results, the changes in the relative humidity which are co-located with the LAI anomaly correspond in general to a bias reduction in comparison with the operational analysis relative humidity (Figure 11d).

In the case of the FNRT forecast experiment where both LAI and albedo NRT analysis are used, the results are quite similar to the FLAINRT experiment where only LAI inter-annual variability is represented through the NRT analysis and albedo is climatology (Figure 12). The only noticeable difference can be seen over central and eastern Australia where the negative albedo anomaly occurs; in this case the cooling/moistening (Figure $11 \mathrm{a} / \mathrm{b}$ ) caused by the LAI positive anomaly is reduced and even reversed compared to FLAINRT (Figures 12a/b). This can be explained by the darkening of the surface albedo (Figure 5c), which causes an increase of the absorbed surface radiation and consequently an increase in the sensible heat flux as depicted in the offline experiment (Figure 9). The positive impact related to this sensitivity is in general preserved (Figure 12c,d) except in central Australia where the warming/drying mildly increases the temperature/relative humidity bias compared to the operational analysis.

An additional analysis is performed to investigate a possible link between the precipitation field and the LAI and albedo NRT anomalies. Figure 13 shows the day-3 precipitation ( $48-72 \mathrm{~h}$ ) from the forecast experiment using the climatological data (FCLIM) and the differences of the experiments where LAI and albedo are from the NRT analysis with respect to FCLIM. Although the overall pattern does not differ much between the plots (Figure 13b, c ,d), small differences can be noticed in some regions. The use of LAI NRT (Figure 13b, c) results in a decrease of the precipitation over the Horn of Africa and a slightly mixed signal with a predominant overall increase over central and eastern Australia. On the other hand, the albedo anomaly, although having a slight impact on the evaporation (Figure 8), was not translated into a precipitation anomaly (Figure 13b, d). The above- 
mentioned correlation between the LAI and evaporation anomalies and precipitation patterns in some

460 regions suggest that precipitation in those regions is partially driven by evaporation through local 461 surface-atmosphere interaction mechanism. For instance, in the case of the Horn of Africa, Dutra et al. 462 (2013) showed that precipitation in that region is driven by ENSO but also by local surfaceatmosphere interaction. However this is not true everywhere; in other regions like central South America the differences in evaporation (Figure 9) are not correlated with the differences in precipitation.

In addition, this precipitation pattern linked to anomalous LAI regions is already established even at the 24-h forecast range. This suggest that precipitation is sensitive to the surface conditions even at the short range and that the initialisation of surface conditions from offline simulations results is effective in overcoming the surface spin-up problem.

\section{Discussion and Conclusions}

471 Owing to the importance of the vegetation in the land-atmosphere interaction processes, numerous studies have tried to use the satellite observations to give information on the vegetation state, and attempted to evaluate the quality of this information through their signals and impacts. This study proposes an optimal interpolation analysis of the GEOV1 surface albedo and LAI through the combination of the satellite observations and derived climatologies. This assimilation system is able to correct deficiencies in the satellite observation product, especially in high latitudes and snow covered areas as well as in the cloud-contaminated areas. The final products have smoother spatial and temporal evolution, which make them more appropriate for environmental and numerical weather prediction. In addition, although a direct comparison with true observations was not possible due to data availability, we believe that considering the error information within the optimal interpolation system results in a better quality analysis products given that the original GEOV1 products have already been shown to have reasonable accuracy against other global products and sites observations 
events where in wet cases the LAI could be well beyond the 90th percentiles and in dry cases it could be below the 10th percentiles of the considered 14 years' time series. This was also the case for the surface albedo but extremes values are in the opposite direction as albedo decreases in wet cases and increases in dry conditions. In addition, the inter-annual variability of LAI and albedo are more pronounced over regions with low vegetation, which could be explained by the impact of the tighter link between the underlying soil moisture and low vegetation growth in comparison with the high vegetation one, as well as the relation with the background soil exposure and cover.

Given the important role of LAI and albedo in the radiative forcing and the surface energy and water budgets, it is expected that, compared to the climatological fields, the use of NRT LAI and albedo analysis would have an impact on surface carbon and energy fluxes and subsequently affect the prediction of the near-surface temperature and humidity. To asses such impact, two types of global model experiments (stand-alone surface simulation and medium-range forecasts) were performed using the NRT analysis products. The offline surface runs show that extreme NRT LAI anomalies have a strong impact on the surface energy and $\mathrm{CO}_{2}$ fluxes, larger than the albedo anomalies which have a smaller range. In addition, an evaluation against in-situ observations showed that a neutral to slightly better fit with in-situ surface soil moisture (from ISMN) and surface energy and $\mathrm{CO}_{2}$ fluxes (from FLUXNET) can be obtained when using the NRT analysis products although the average signal can be weakened from non-anomalous areas/sites.

The evaluation of using the NRT LAI and albedo analysis in forecast runs shows an overall positive impact on the near-surface air temperature and humidity especially in areas where the LAI anomaly is pronounced. In these cases, the near-surface air temperature and humidity errors, both in wet and dry conditions, are reduced. It is also shown that NRT albedo, given its reduced inter-annual variability, has a smaller impact which is mainly seen in wet cases when albedo anomalies are more pronounced. The impact on precipitation fields revealed that in some regions the differences in precipitations fields, evapotranspiration and NRT LAI are correlated. In these regions, the local surface-atmosphere 
509 interaction is believed to be one of the important drivers for precipitation, however further

510 investigation supported by additional in-situ observation is needed to confirm such hypothesis.

511 The offline surface runs and forecasts experiments confirm the benefit coming from a more realistic 512 treatment of vegetation by the use of NRT LAI and albedo analysis. With NRT analysis products, 513 anomalous years could be detected and surface fluxes were directly affected by their inter-annual 514 variability. The forecast simulation confirmed this positive impact on the near-surface weather 515 parameters and its potential to account for NRT issues such us a rapid change in the LAI due to fast 516 growth or harvest as well as inter-annual variability due to an extreme drought or an extensive snow 517 season that may inhibit growth.

518 However, some caveats on the generality of these results within the ECMWF modelling system are to 519 be mentioned. For instance ad-hoc separations of momentum budget from vegetation cycle are 520 currently adopted (e.g. a constant vegetation roughness length per given vegetation type, Sandu et al. 521 2013) and may artificially reduce the sensitivity to vegetation state anomalies. Similarly the 522 interaction of albedo, considering broadband anomalies is less sensitive to vegetation variability than considering only the near infrared component (Gao et al., 2005). In addition, the treatment of albedo in presence of snow (using a climatological vegetation albedo per given type, Dutra et al. 2010) reduces the impact of albedo anomalies for early/late senescence or greening. Nevertheless, both the effects discussed above, related to LAI and albedo treatment in the modelling system, are going towards a reduction of atmospheric impact. Therefore they reinforce the hypothesis of meaningful influence of the vegetation and albedo on weather prediction. Furthermore, despite the overall good performance of the assimilation system especially in detecting the global inter-annual variability of the albedo and the LAI, we believe that introducing a prognostic model for these variables as a background information within such a system would still reduce the noise signal especially where the observation and/or the climatological values have large errors and allow more flexibility in predictive 
mode. This is only possible when a prognostic vegetation evolution is introduced, which is being considered in a future study.

\section{Acknowledgements:}

We thank Patricia de Rosnay, Peter Bechtold, Roselyne Lacaze and Jean Christophe Calvet for their support and fruitful comments on the results, Anabel Bowen for her help on the figures improvements and Bob Riddaway for his careful review and improvements of the use of the English language. We also thank Iain Russell and Sandor Kertesz for their support with METVIEW. We would also like to thank the anonymous reviewers who made valuable suggestions that led to improve the paper. This work used eddy covariance data acquired by the FLUXNET community and in particular by the following networks: AmeriFlux (U.S. Department of Energy), Biological and Environmental Research, Terrestrial Carbon Program (DE-FG02-04ER63917 and DE-FG02-04ER63911), CarboItaly, CarboMont, Fluxnet-Canada (supported by The Canadian Foundation for Climate and Atmospheric Sciences (CFCAS), The Natural Sciences and Engineering Research Council of Canada (NSERC), BIOCAP Foundation, Environment Canada, and Natural Resources Canada (NRCan)), the Sources and Sinks of Greenhouse Gases from managed European Grasslands and Mitigation Strategies (GreenGrass) project, the Large-scale Biosphere-Atmosphere Experiment in Amazonia (LBA), the Nordic Centre for Studies of Ecosystem carbon exchange and its Interaction with the Climate system (NECC), the Terrestrial Carbon Observation System Siberia (TCOS-Siberia). We thank in particular the PIs that decided to share their data freely within the scientific community. We acknowledge the support to the eddy covariance data harmonization provided by the Integrated Project Assessment of the European Terrestrial Carbon Balance (CarboEuropeIP), The Food and Agriculture Organization-The Global Terrestrial Observing System-The Terrestrial Carbon Observations project (FAO-GTOS-TCO), the Integrated Land Ecosystem-Atmosphere Processes Study (iLEAPS), Max Planck Institute for Biogeochemistry, National Science Foundation, University 
of Tuscia, Université Laval and Environment Canada and US Department of Energy and the database development and technical support from Berkeley Water Center, Lawrence Berkeley National Laboratory, Microsoft Research eScience, Oak Ridge National Laboratory, University of California Berkeley, University of Virginia. We also thank The Fluxnet-Canada Research Network for making available the BERMS data ( http://berms.ccrp.ec.gc.ca/Overview/e-overview-about.htm ), the PIs and researchers involved in the Coordinated Enhanced Observing Period (CEOP) project for provision and archiving of the data used in this study ( http://www.ceop.net/ ), and the CARBOSCOPE project contributors for making their data freely available through the project website ( http://www.carboscope.eu/?q=home ). We thank also all the PIs of the International Soil Moisture Network (ISMN) that decided to share their data freely within the scientific community (https://ismn.geo.tuwien.ac.at/ismn/). We further thank Bruno Smets from VITO for his support on the GEOV data provision (http://land.copernicus.eu/global/). This work is a contribution to the ImagineS project (http://fp7-imagines.eu/), funded by the European Commission $7^{\text {th }}$ Framework Programme in support to the Copernicus Global land.

\section{References}

Avissar, R., \& Liu, Y. (1996). Three-dimensional numerical study of shallow convective clouds and precipitation induced by land surface forcing. J.of Geophys. Res., 101, 7499-7518.

Baldocchi, D., et al., (2001). FLUXNET: A new tool to study the temporal and spatial variability of ecosystem-scale carbon dioxide, water vapor, and energy flux densities. Bull. Am. Meteorol. Soc., 82, 2415-2434, doi:10.1175/1520-0477.

Baldocchi D., (2008). Breathing of the terrestrial biosphere: lessons learned from a global network of carbon dioxide flux measurement systems. Aust. J. Bot., 56, 1-26.

Balsamo, G., Viterbo, P., Beljaars, A., van den Hurk, B., Hirschi, M., Betts, A. K., \& Scipal, K. (2009). A Revised Hydrology for the ECMWF Model: Verification from Field Site to Terrestrial Water Storage and Impact in the Integrated Forecast System. J. Hydrometeor., 10, 623-643. 
Balsamo, G., Boussetta, S., Dutra, E., Beljaars, A., Viterbo, P. \& Van den Hurk, B. (2011). Evolution of land surface processes in the IFS, ECMWF Newsletter, 127, 17-22.

Baret, F. and Weiss, M., (2014). ATBD of the Copernicus Global Land GEOV1 data: LAI, FAPAR, NDVI and Fcover. Copernicus Global Land Services documentations, http://land.copernicus.eu/global/sites/default/files/products/GIOGL1_ATBD_LAIV1_I1.10.pdf.

Baret, F., Weiss, M., Lacaze, R., Camacho, F., Makhmara, H., Pacholcyzk, P., et al., (2013). GEOV1: LAI and FAPAR essential climate variables and FCOVER global time series capitalizing over existing products. Part1: Principles of development and production. Rem. Sens. Envir., 137, 299309, http://dx.doi.org/10.1016/j.rse.2012.12.027.

Baret, F., Hagolle, O., Geiger, B., Bicheron, P., Miras, B., Huc, M., Berthelot, B., Niño, F., Weiss, M., Samain, O., Roujean, J. L., \& Leroy, M. (2007). LAI, fAPAR and fCover CYCLOPES global products derived from VEGETATION. Part 1: Principles of the algorithm. Rem. Sens. Envir., 110, $530275-286$.

Beljaars, A., Viterbo, P., Miller, M., \& Betts, A. K. (1996). The anomalous rainfall over the United States during July 1993: Sensitivity to land surface parameterization and soil moisture anomalies, Mon. Weather Rev., 124, 362-383.

Bell, J. E., Palecki, M. A., Baker, C. B., Collins, W. G., Lawrimore, J. H., Leeper, R. D., Hall, M. E., Kochendorfer, J., Meyers, T. P., Wilson, T. \& Diamond, H. J. (2013). U.S. Climate Reference Network soil moisture and temperature observations. J. Hydrometeorol., 14, 977-988. doi: 10.1175/JHM-D-12-0146.1, 2013.

Berbet, M. L. C. \& Costa, M. H. (2003). Climate Change after Tropical Deforestation: Seasonal Variability of Surface Albedo and Its Effects on Precipitation Change. J. Climate, 16, 2099-2104. doi: http://dx.doi.org/10.1175/1520-0442(2003)016<2099:CCATDS>2.0.CO;2

Betts, A.K., Ball, J.H., Beljaars, A., Miller, M., \& Viterbo, P., (1996). The land-surface-atmosphere interaction: A review based on observational and global modelling perspective. J. Geophys. Res., $101,7209-7225$.

Betts, A.K., Ball, J.H., Barr, A. G., Black, T. A., McCaughey, J. H. \& Viterbo, P. (2006). Assessing land-surface-atmosphere coupling in the ERA-40 re-analysis with boreal forest data. Agric. For. Meteorl., 140, 355-382. 
Boussetta, S., Koike, T., Kun, Y., Graf, T. \& Pathmathevan, M. (2008). Development of a coupled land-atmosphere satellite data assimilation system for improved local atmospheric simulations. Rem. Sens. Envir., 112, 720-734.

Boussetta, S., Balsamo, G., Beljaars, A., Kral, T. \& Jarlan, L. (2013a). Impact of a satellite-derived Leaf Area Index monthly climatology in a global Numerical Weather Prediction model, Int. J. Rem. Sens., 34 (9-10), 3520-3542.

Boussetta, S. et al., (2013b). Natural land carbon dioxide exchanges in the ECMWF Integrated Forecasting System: Implementation and Offline validation. J. Geophys. Res. 118, 1-24. doi:10.1002/jgrd.50488.

Camacho, F., Cernicharo, J., Lacaze, R., Baret, F. \& Weiss, M. (2013). GEOV1: LAI, FAPAR Essential Climate Variables and FCOVER global time series capitalizing over existing products. Part 2: Validation and intercomparison with reference products. Rem. Sens. Envir. 137, 310-329, http://dx.doi.org/10.1016/j.rse.2013.02.030.

Deardorff, J.W., (1978). Efficient prediction of ground surface temperature and moisture, with inclusion of a layer of vegetation. J. Geophys. Res., 83, 1889-1903.

Dee, D. P., et al., (2011). The ERA-Interim reanalysis: Configuration and performance of the data assimilation system, Q. J. R. Meteorol. Soc., doi: 10.1002/qj.828.

Dorigo, W. A., Wagner, W., Hohensinn, R., Hahn, S., Paulik, C., Xaver, A., Gruber, A., Drusch, M., Mecklenburg, S., van Oevelen, P., Robock, A., \& Jackson, T. (2011). The International Soil Moisture Network: a data hosting facility for global in situ soil moisture measurements, Hydrol.

Dorman, J.L. \& Sellers, P. J. (1989). A Global Climatology of Albedo, Roughness Length and Stomatal Resistance for Atmospheric General Circulation Models as Represented by the Simple Biosphere Model (SiB). J. Appl. Meteorol., 28, 833-855.

Dutra, E., Balsamo, G., Viterbo, P., Miranda, P.M.A., Beljaars, A., Schär, C., Elder, K., (2010). An improved snow scheme for the ECMWF land surface model: description and offline validation. $J$. Hydrometeor. 11, 899-916. doi: 10.1175/2010JHM1249.1. 
Dutra, E., Magnusson, L., Wetterhall, F., Cloke, H. L., Balsamo, G., Boussetta, S. \& Pappenberger, F. (2013). The 2010-2011 drought in the Horn of Africa in ECMWF reanalysis and seasonal forecast products. Int. J. Climatol., 33, 1720-1729. doi: 10.1002/joc.3545.

Fang, H., Wei, S., \& Liang, S. (2012). Validation of MODIS and CYCLOPES LAI products using global field measurement data. Rem. Sens. Envir., 119, 43-54. doi:10.1016/j.rse.2011.12.006.

Fang, H., et al. (2013). Characterization and intercomparison of global moderate resolution leaf area index (LAI) products: Analysis of climatologies and theoretical uncertainties, J. Geophys. Res. Biogeosci., 118, 529-548, doi:10.1002/jgrg.20051.

Gao, F., Schaaf, C., Strahler, A., Roesch, A., Lucht, W., \& Dickinson, R. (2005). The MODIS BRDF/Albedo Climate Modeling Grid Products and the Variability of Albedo for Major Global Vegetation Types, J. Geophys. Res., 110, D01104, doi:10.1029/2004JD00519.

Garrigues S., Lacaze, R., Baret, F., Morisette, J. T., Weiss, M., Nickeson, J. E., Fernandes, R., Plummer, S., Shabanov, N. V., Myneni, R. B., Knyazikhin, Y., \& Yang, W. (2008). Validation and intercomparison of global Leaf Area Index products derived from remote sensing data. J. Geophys. Res., 113, G02028, doi:10.1029/2007JG000635.

Geiger, B. \& Samain, O. (2004). Albedo determination, Algorithm Theoretical Basis Document, of the CYCLOPES project, version 2.0, 25p. Météo-France/CNRM.

Giard, D. \& Bazile, E. (2000). Implementation of a new assimilation scheme for soil and surface variables in a Global NWP model. Mon.Weath. Rev., 128, 997-1015.

Gu, Y., Belair, S., Mahfouf, J.-F., and Deblonde, G. (2006). Optimal interpolation analysis of leaf area index using MODIS data. Rem. Sens. Envir., 104, 283-296, doi:10.1016/j.rse.2006.04.021.

Guillevic, P., Koster, R. D., Suarez, M. J., Bounoua, L., Collatz, G. J., Los, S. O., \& Mahanama, S.P.P. (2002). Influence of the interannual variability of vegetation on the surface energy balance a global sensitivity study. J. Hydrometeor., 3, 617-629.

Hagolle, O., Lobo, A., Maisongrande, P., Cabot, F., Duchemin, B., de Pereyra, A. (2004). Quality assessment and improvement of temporally composited products of remotely sensed imagery by combination of VEGETATION 1 and 2 images. Rem. Sens. Envir, 94, 172-186.

Kallberg, P., (2011), Forecast drift in ERA-Interim, ERA report series, No 10, http://www.ecmwf.int/publications /library/ecpublications/_pdf/era/era_report_series/RS_10.pdf 
Knote, C., Bonafe, G., \& DI Guiseppe, F. (2009). Leaf Area Index Specification for Use in Mesoscale Weather Prediction Systems. Mon. Weath. Rev., 137, 3535-3550.

Koster, R. D., Mahanama, S., Yamada, T., Balsamo, G., Boisserie, M., et al., (2010). The Contribution of Land Surface Initialization to Subseasonal Forecast Skill: First Results from the GLACE-2 Project, Geophys. Res. Lett., 37, L02402, doi:10.1029/2009GL041677.

Lacaze, R., (2014). ATBD of the Copernicus Global Land GEOV1 data: Surface Albedo, Copernicus Global Land Services documentations, http://land.copernicus.eu/global/sites/default/files/products/ GIOGL1_ATBD_SAV1_I1.01.pdf.

Lawrence, D. M. \& Slingo, J. M. (2004). An annual cycle of vegetation in a GCM. Part I: implementation and impact on evaporation, Clim. Dynam., 22, 87-105.

Loveland, T. R., Reed, B. C., Brown, J. F., Ohlen, D. O., Zhu, Z., Youing, L., \& Merchant, J. W. (2000). Development of a global land cover characteristics database and IGB6 DISCover from the 1 km AVHRR data. Int. J. Rem. Sens., 21, 1303-1330.

Myneni, R. B., Hoffman, S., Knyazikhin, Y., Privette, J. L., Glassy, J., Tian, Y., Wang, Y., Song, X., Zhang, Y., Smith, G. R., Lotsch, A., Friedl, M., Morisette, J. T., Votava, P., Nemani, R. R., Running, S. W. (2002). Global products of vegetation leaf area and fraction absorbed PAR from year one of MODIS data. Rem. Sens. Envir., 83, 214-231.

Pielke, R. A., \& Avissar, R. (1990). Influence of landscape structure on local and regional climate, Landscape Ecol., 4, 133-155, doi:10.1007/BF00132857.

Preuss, H. J., \& Geleyn, J. F. (1980). Surface albedos derived from satellite data and their impact on forecast models, Meteorol. Atmos. Phys., 29A, 345-356, doi:10.1007/BF02245431.

Rahman, H. \& Dedieu, G. (1994). SMAC: a simplified method for the atmospheric correction of satellite measurements in the solar spectrum. Int. J. Rem. Sens., 15(1): 123-143.

Roujean, J.-L., Leroy, M. \& Deschamps, P.-Y. (1992). A bidirectional reflectance model of the Earth's surface for the correction of remote sensing data. J. Geophys. Res., 97(D18), 20455-20468.

Rowell D. P., \& Blondin, C. (1990), The influence of soil wetness distribution on short-range rainfall forecasting in the West African Sahel. Q. J. R. Meteorol. Soc., 116, 496, 1471-1485. DOI: 10.1002/qj.49711649611. 
Sandu, I., Beljaars A., Bechtold P., Mauritsen T. \& Balsamo G. (2013), Why is it so difficult to represent stably stratified conditions in numerical weather prediction (NWP) models?, $J$. Adv. Model. Earth Syst., 5, 117-133, doi:10.1002/jame.20013.

Sellers, P.J., Los, S. O., Tucker, C. J., Justice, C. O., Dazlich, D. A., Collatz, G. J. \& Randall, D. A., (1996). A revised land surface parameterization (SiB2) for atmospheric GCMs, Part II: The generation of global fields of terrestrial biophysical parameters from satellite data. J. Clim., 9, 676-705.

Van den Hurk, B., Viterbo, P., \& Los, S. (2003a). Impact of leaf area index seasonality on the annual land surface evaporation in a global circulation model. J. Geophys. Res., 108, D6, 4191, doi:10.1029/2002JD002846.

Van den Hurk, B. \& Viterbo, P. (2003b). The Torne-Kalix PILPS 2(e) experiment as a test bed for modifications to the ECMWF land surface scheme. Global and Planetary Change, 38, 165-173.

Verger, A., Baret, F., Weiss, M. (2011). A multisensor fusion approach to improve LAI time series. Rem. Sens. Enviro., DOI: 10.1016/j.rse.2011.05.

Viterbo, P. \& Beljaars, A. (1995). An improved land surface parametrization scheme in the ECMWF model and its validation, ECMWF Technical Report, 75, Reading, UK.

Viterbo P., Beljaars, A., Mahouf, J.-F., Teixeira, J. (1999). The representation of soil moisture freezing and its impact on the stable boundary layer. Q. J. R. Meteorol. Soc. 125, 2401-2426.

Xue, Y., Fennessy,M.J. \& Sellers, P.J. (1996). Impact of vegetation properties on U.S. Summer weather prediction. J. Geophys. Res., 101D, 7419-7430. 


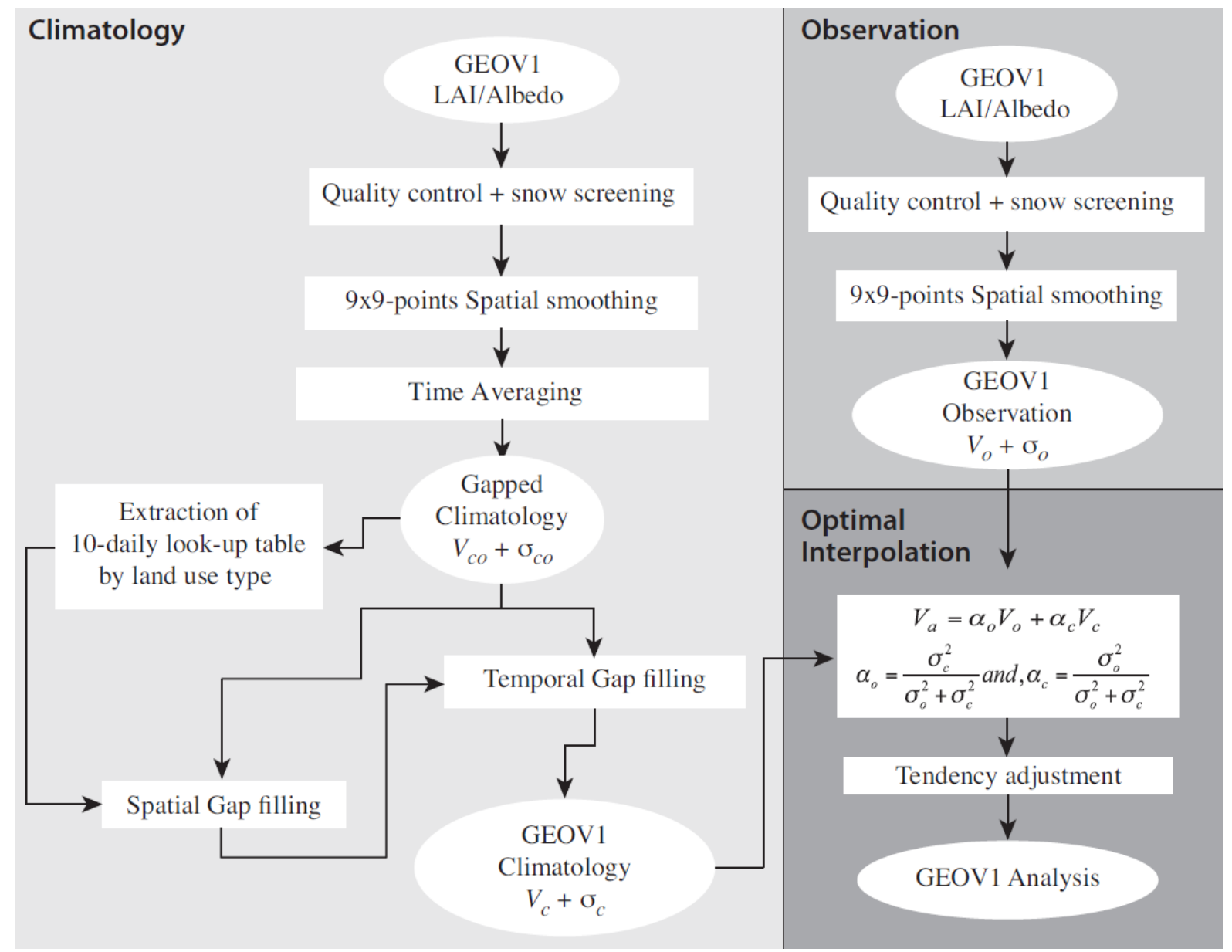

Figure 1: Flowchart of the GEOV1 albedo and LAI pre-processing, climatology derivation and optimal interpolation analysis.

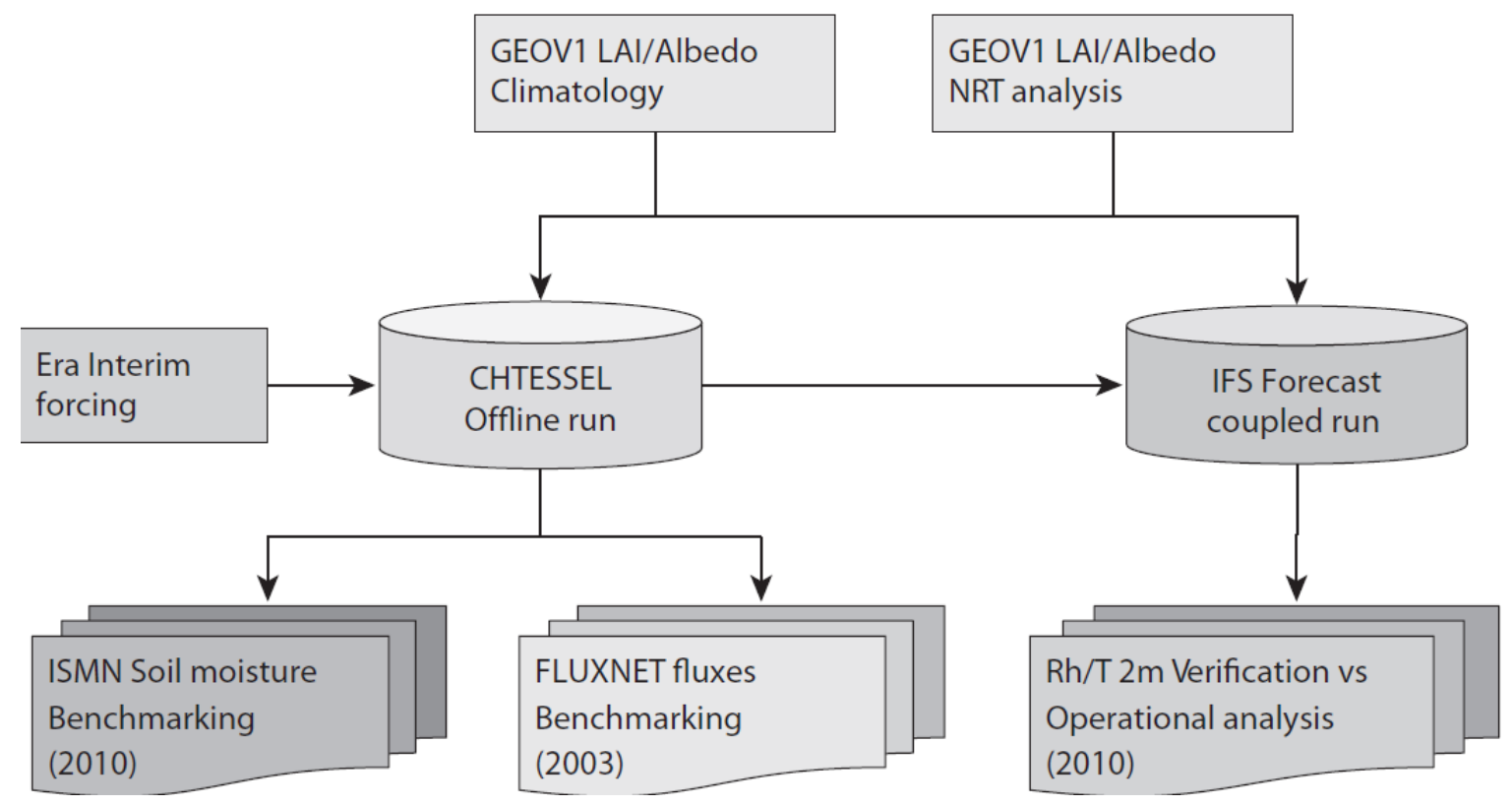

Figure 2: Evaluation procedure of the impact of NRT LAI/albedo analysis. 
a)

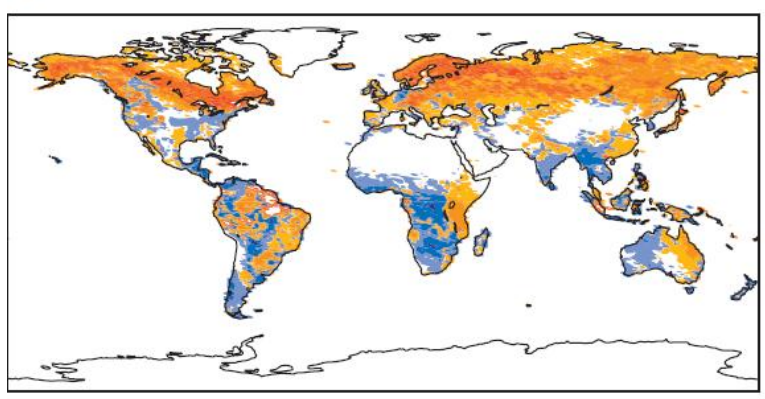

b)

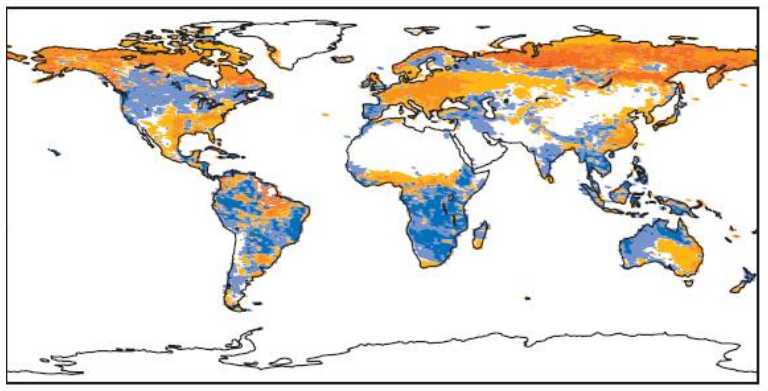

c)

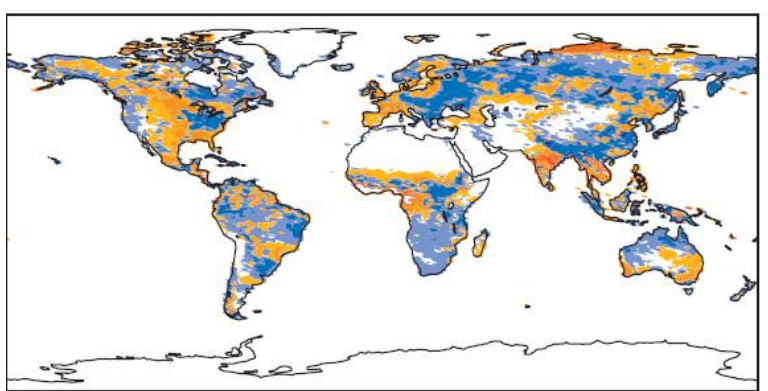

d)
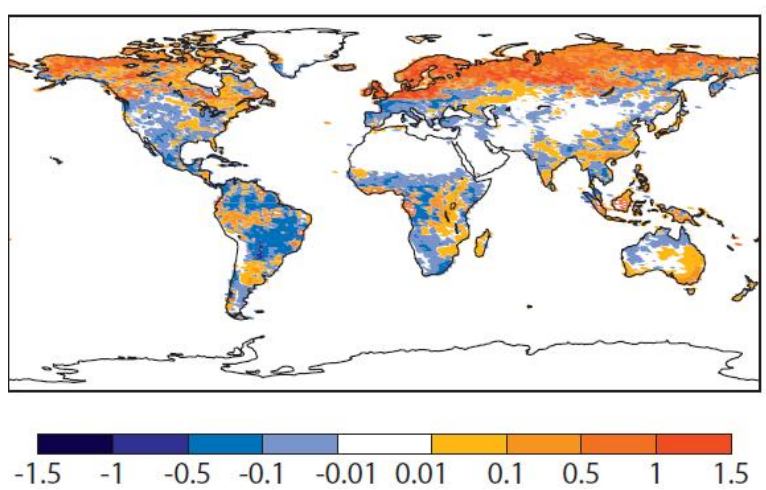

e)

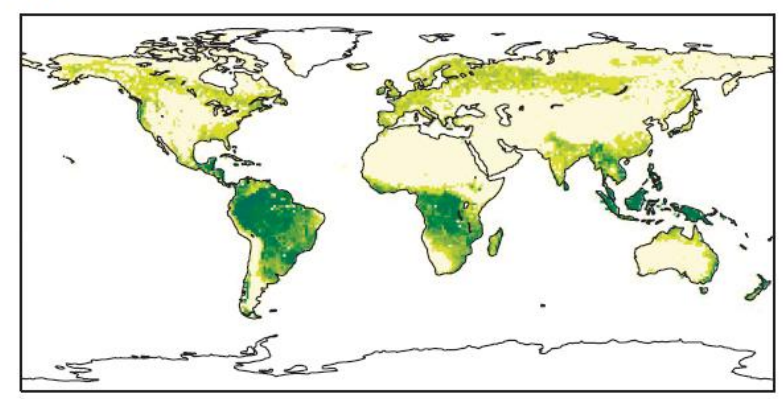

f)

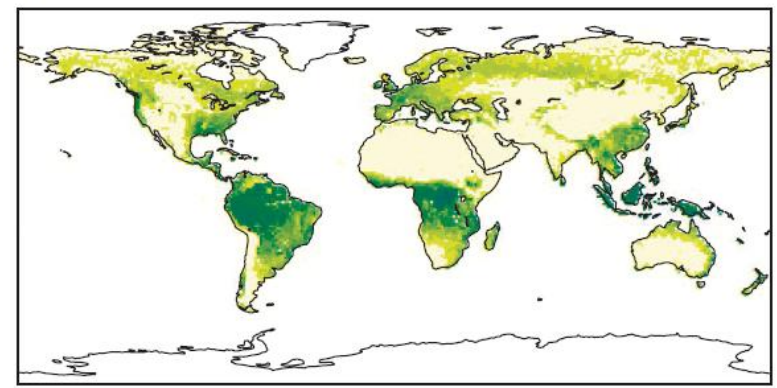

g)

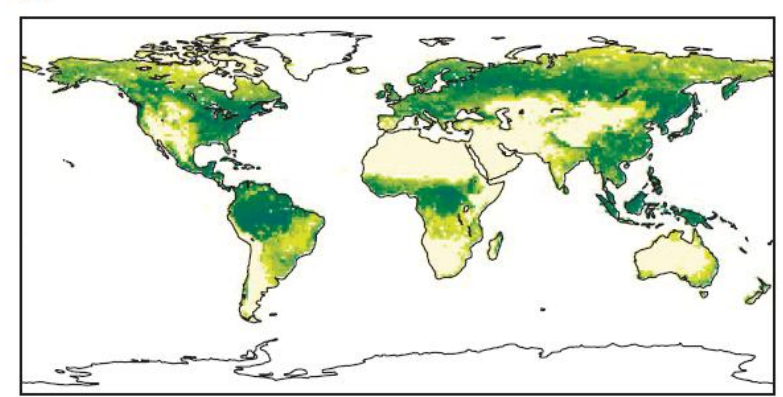

h)

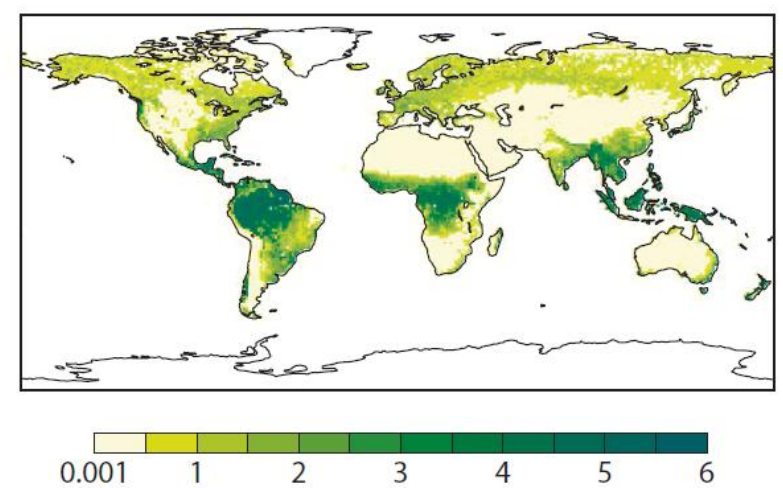

Figure 3: Analysed LAI $\left[\mathrm{m}^{2} \mathrm{~m}^{-2}\right]$ (right column) and differences between analysed and observed LAI [ $\mathrm{m}^{2}$ $\mathrm{m}^{-2}$ ] (left column) for 25 January 2006 (top row), 25 April 2006 (second row), 25 July2006 (third row), and 25 October 2006 (bottom row). 
a)

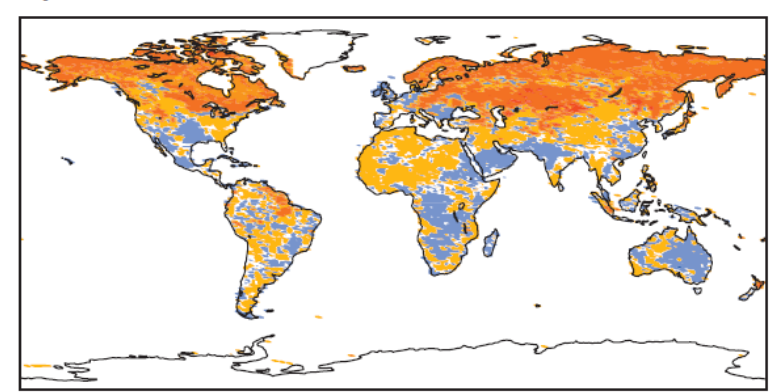

b)

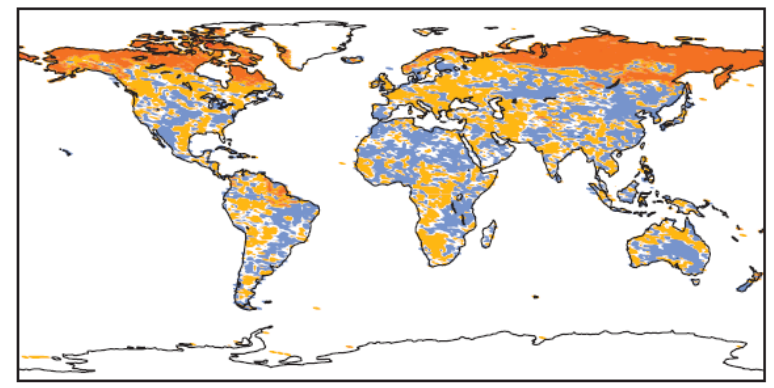

c)

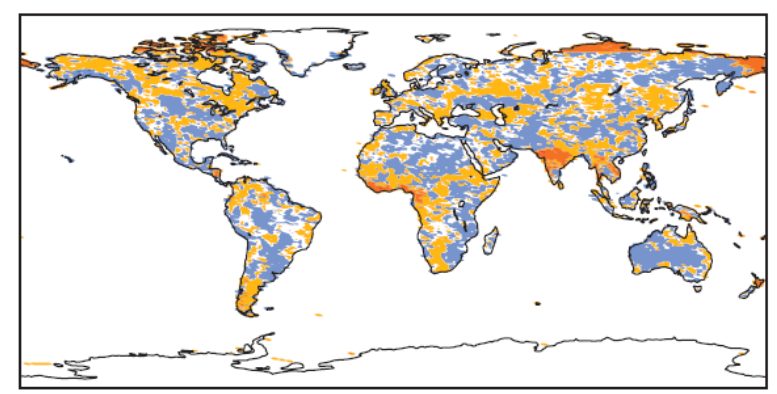

d)

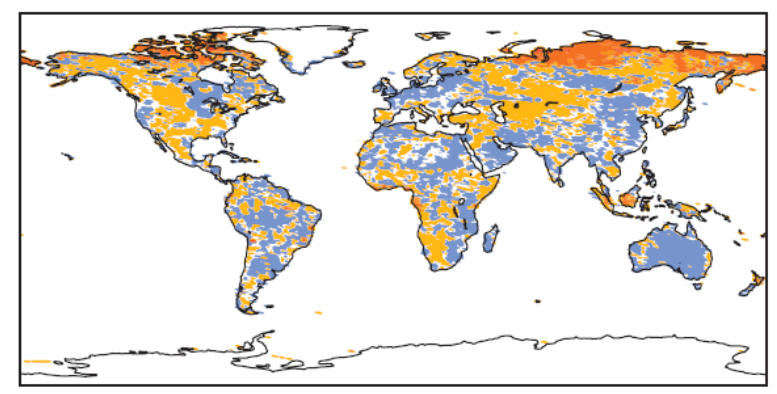

$\begin{array}{llllllllll}-0.5 & -0.2 & -0.1 & -0.05 & -0.001 & 0.001 & 0.05 & 0.1 & 0.2 & 0.5\end{array}$ e)

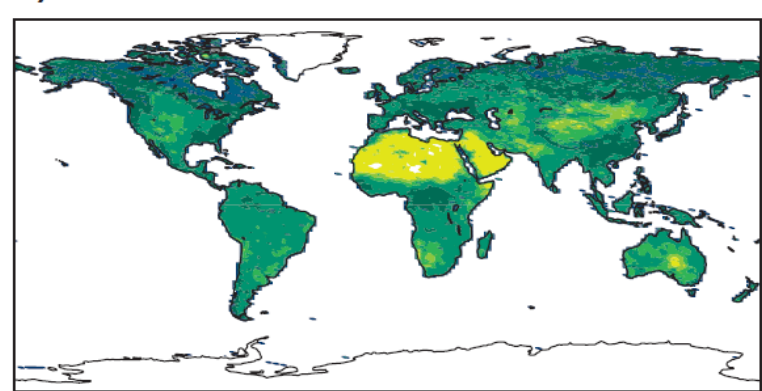

f)

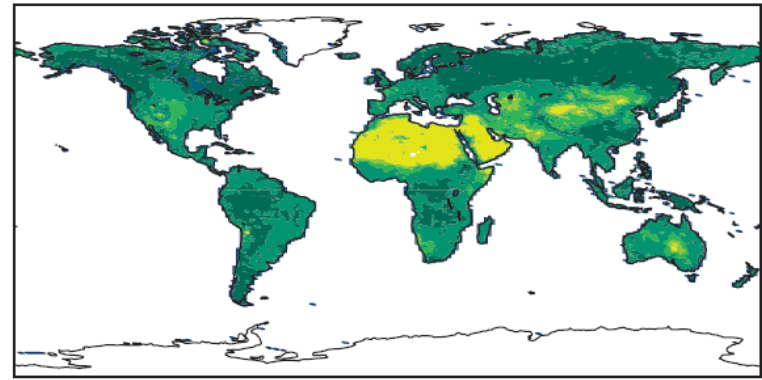

g)

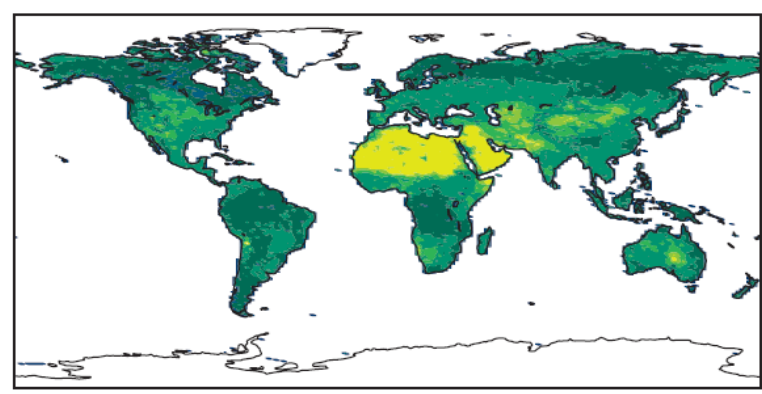

h)

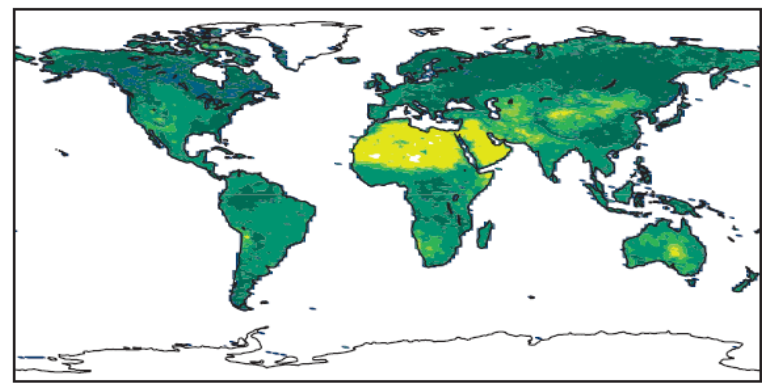

$\begin{array}{lllllllll}0.001 & 0.05 & 0.1 & 0.15 & 0.2 & 0.25 & 0.3 & 0.5 & 0.7\end{array}$

Figure 4: Analysed broadband diffuse albedo (right column) and differences between analysed and observed broadband diffuse albedo (left column) for 25 January 2006 (top row), 25 April 2006 (second row), 25 July2006 (third row), and 25 October 2006 (bottom row). 
a)
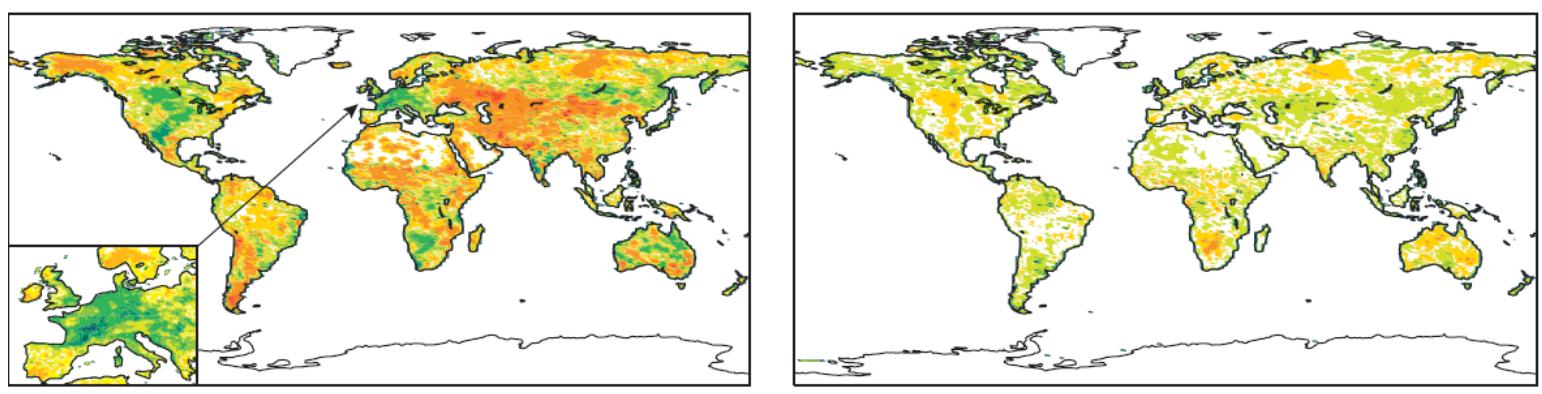

b)
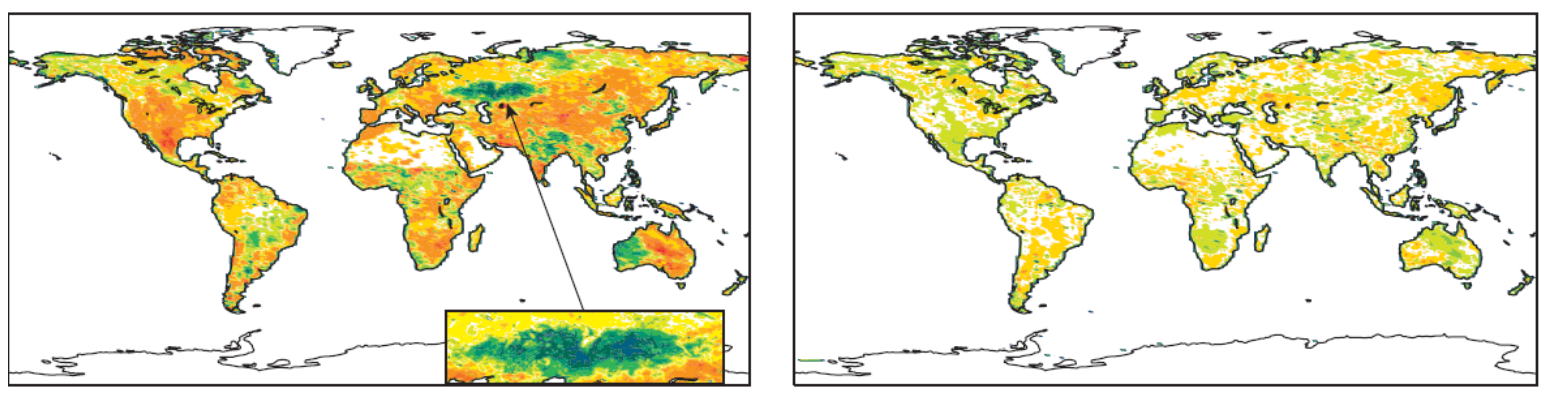

c)
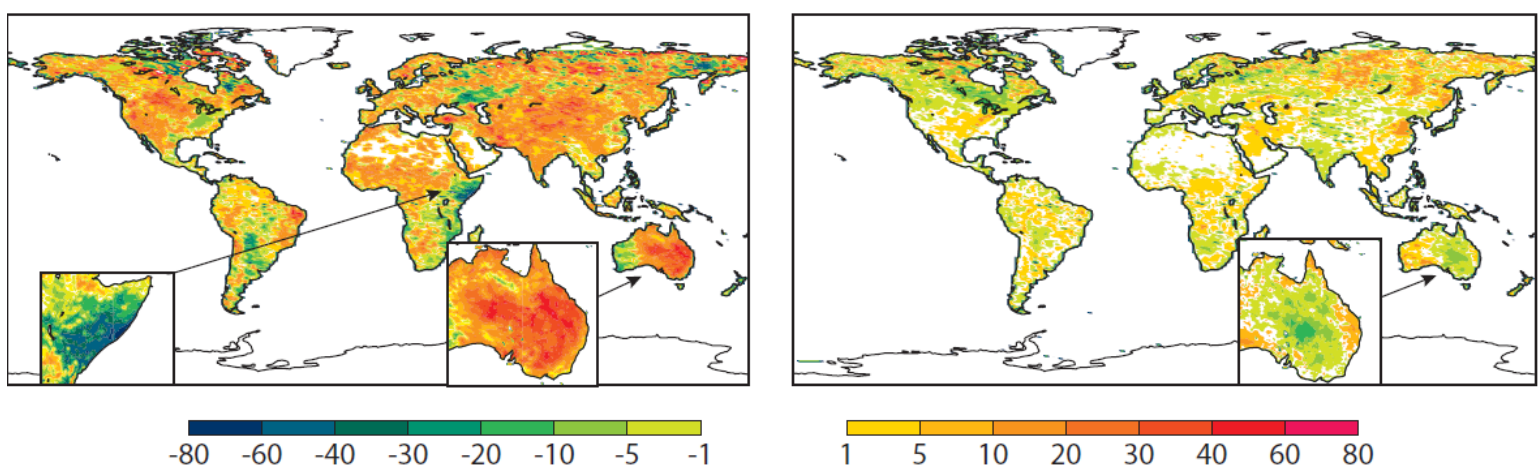

Figure 5: Relative anomaly [\%] with respect to mean (1999-2012) climate of LAI (left) and broadband diffuse albedo (right) for a) August 2003, b) July 2010 and c) November 2010. Regions of interest are zoomed in. 

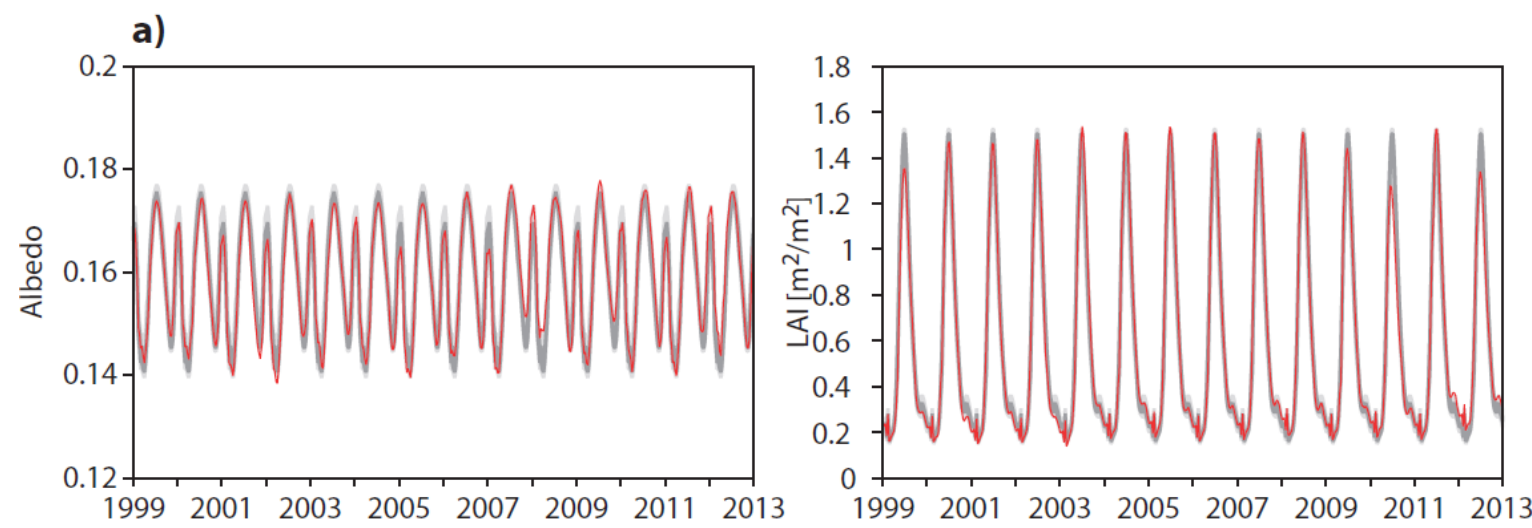

b)
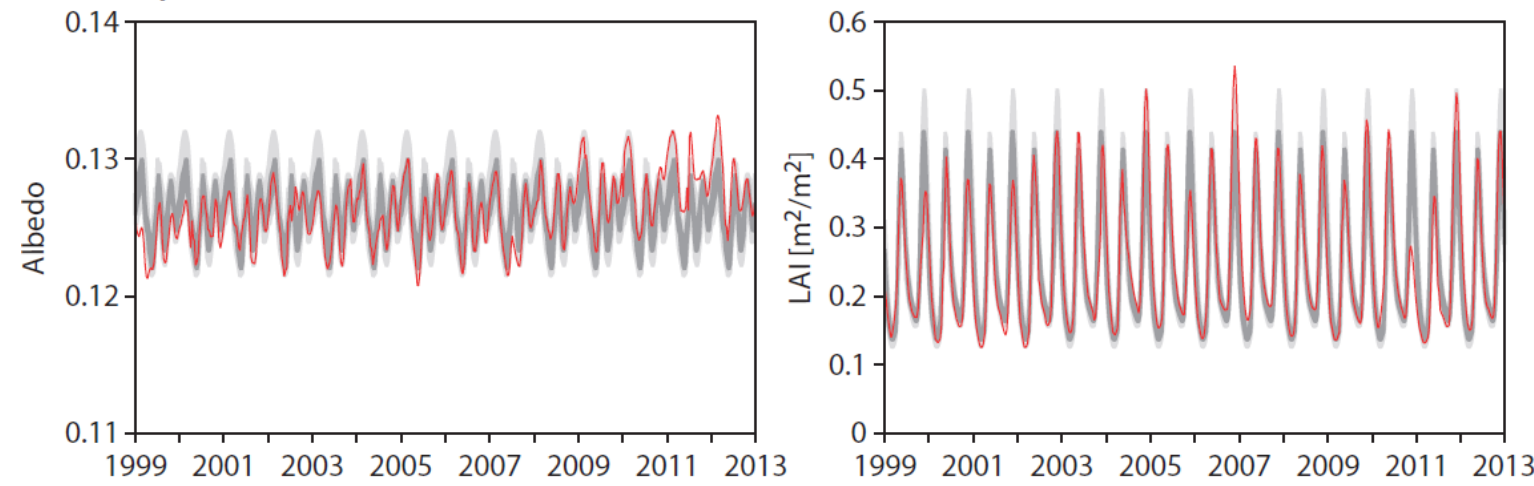

c)
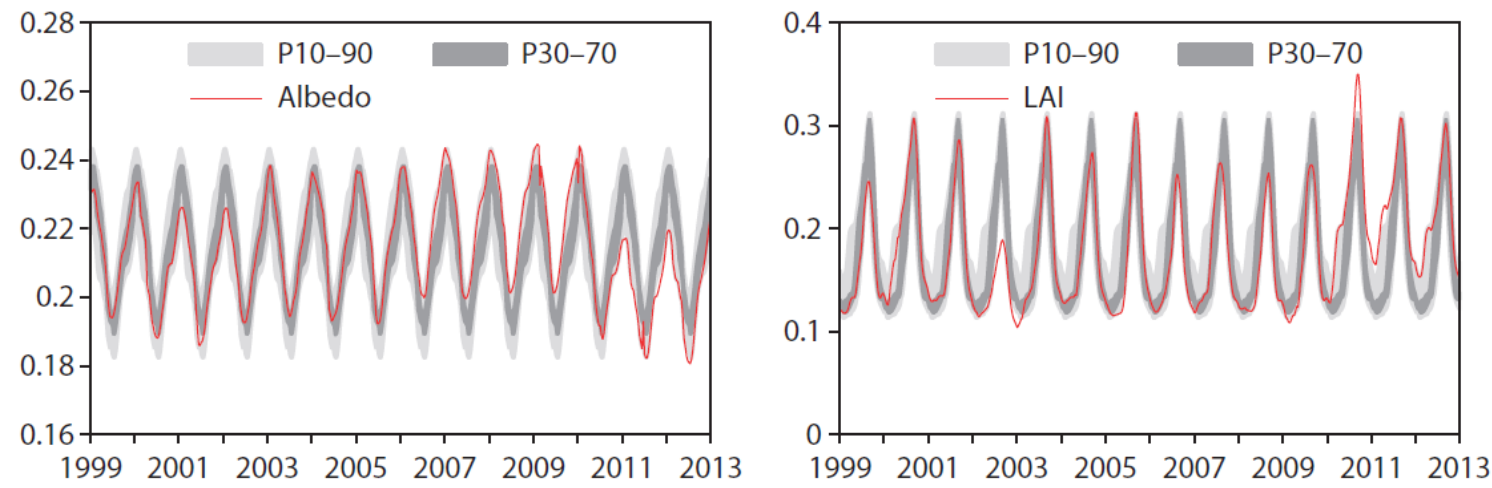

Figure 6: Time series (red) of albedo (left) and LAI (right) for a) Russia, b) Horn of Africa and c) Central Australia. The 10-90th percentile of the climatological distribution are marked in light grey and the 3070th percentile in dark grey. 
a)

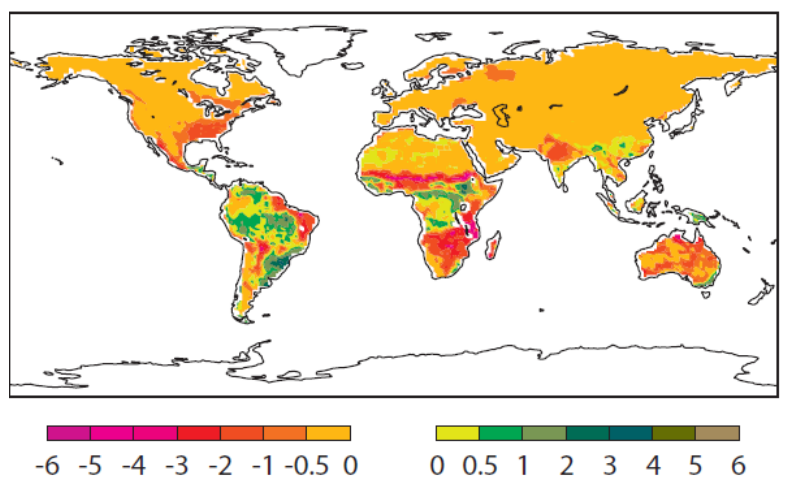

b)

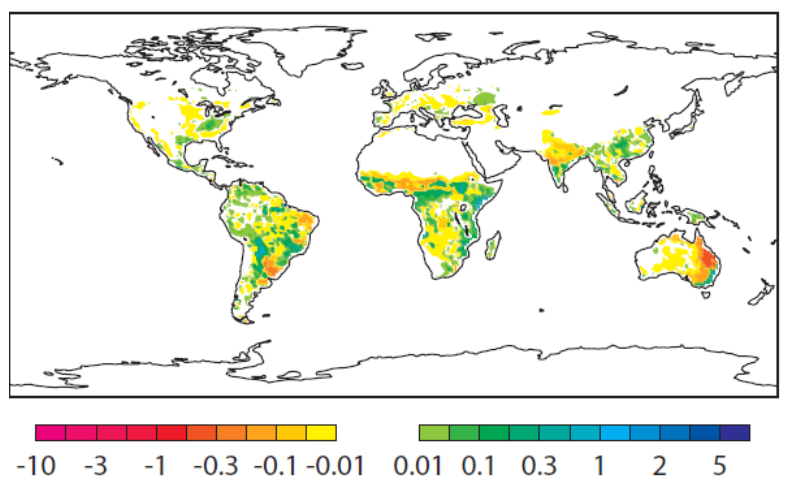

c)

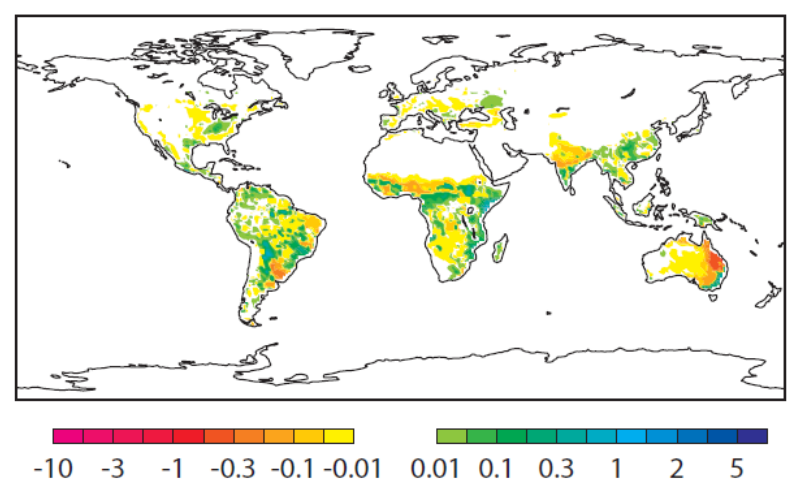

d)

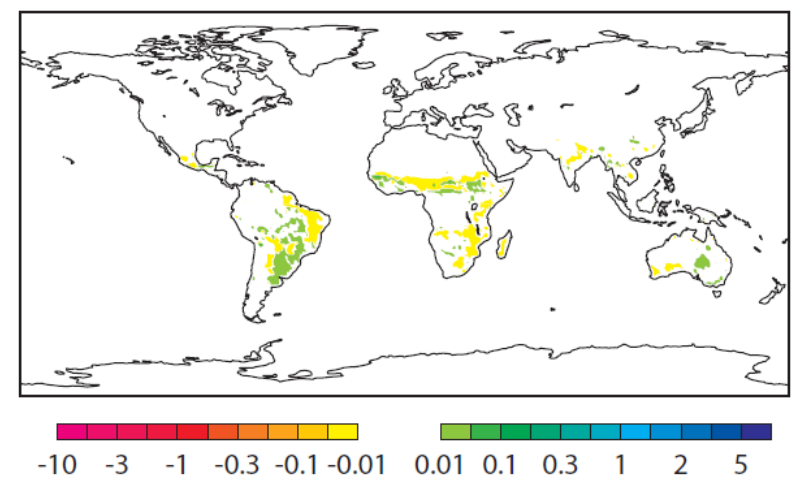

Figure 7: Net Ecosystem exchange [micromoles $\mathrm{m}^{-2} \mathrm{~s}^{-1}$ ] for November 2010, a) using GEOV1 climatological LAI and albedo (SCLIM). Anomalies are shown as differences of absolute fluxes with respect to SCLIM for simulations using b) LAI and albedo NRT analysis (SNRT), c) LAI NRT analysis and albedo climatology (SLAINRT) and d) albedo NRT analysis and LAI climatology (SLABNRT).
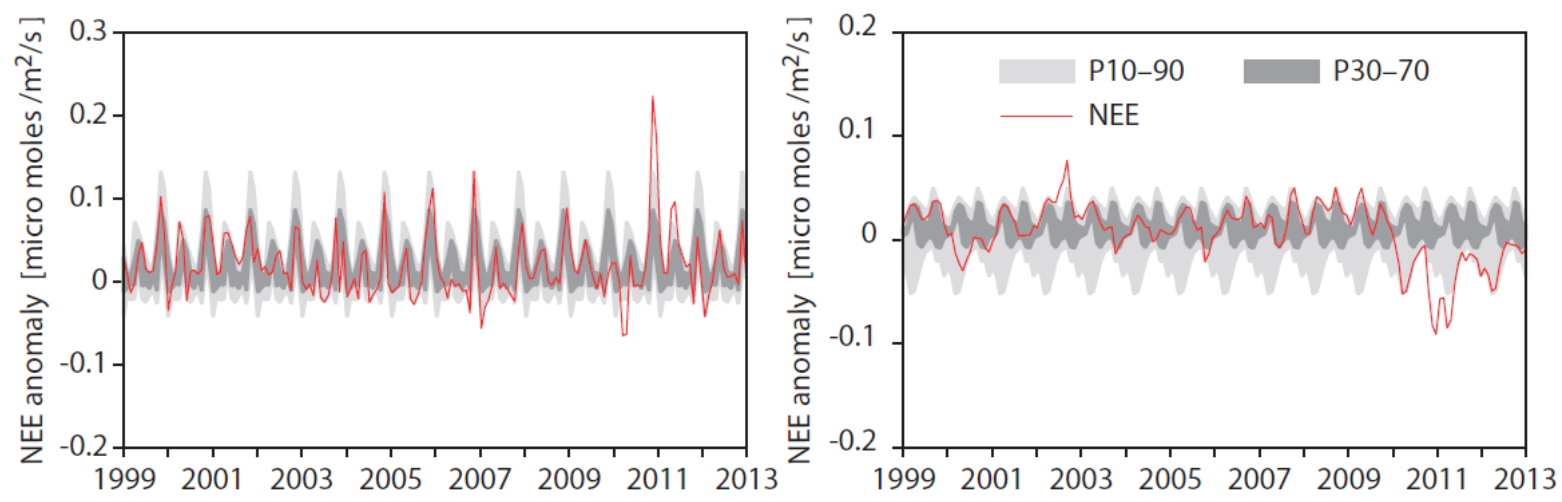

Figure 8: Time series of the Net Ecosystem Exchange anomaly [micromoles $\mathrm{m}^{-2} \mathrm{~s}^{-1}$ ] for the Horn of Africa (left), and for central Australia (right). Anomalies are shown as differences of absolute flux between simulation using climatological LAI and albedo (SCLIM) and simulation using NRT LAI (SLAINRT). 
a)

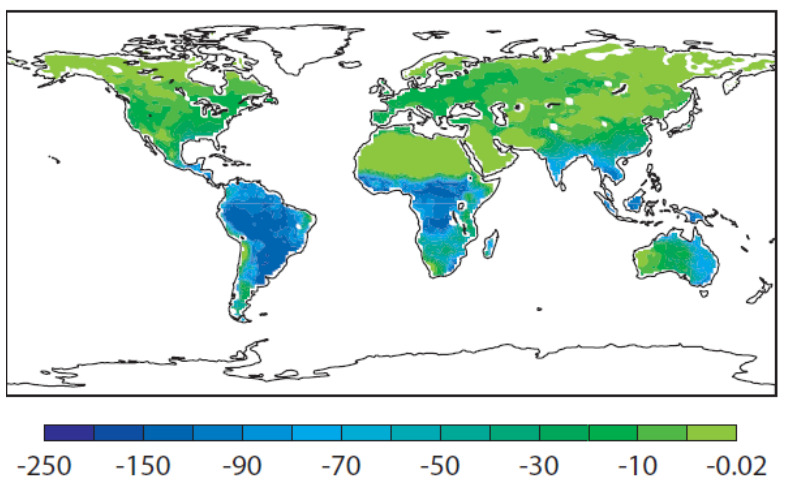

b)

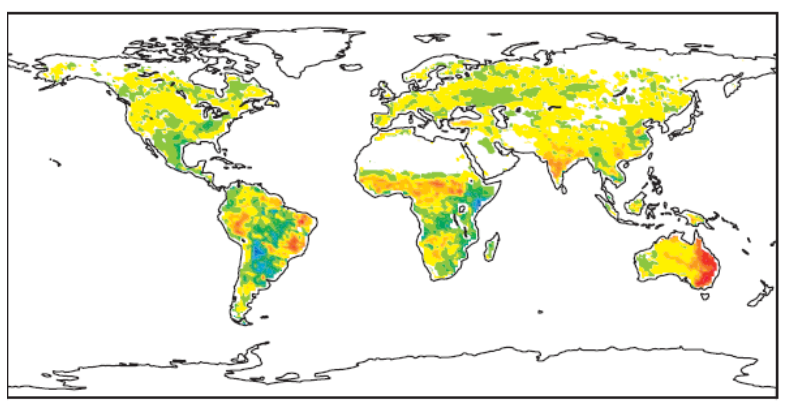

\begin{tabular}{lllllllll|llll|}
\hline & $\mid$ & $\mid$ & $\mid$ & $\mid$ & & & & \\
-20 & -10 & -5 & -2 & -0.01 & 0.01 & 2 & 5 & 10 & 20
\end{tabular} c)

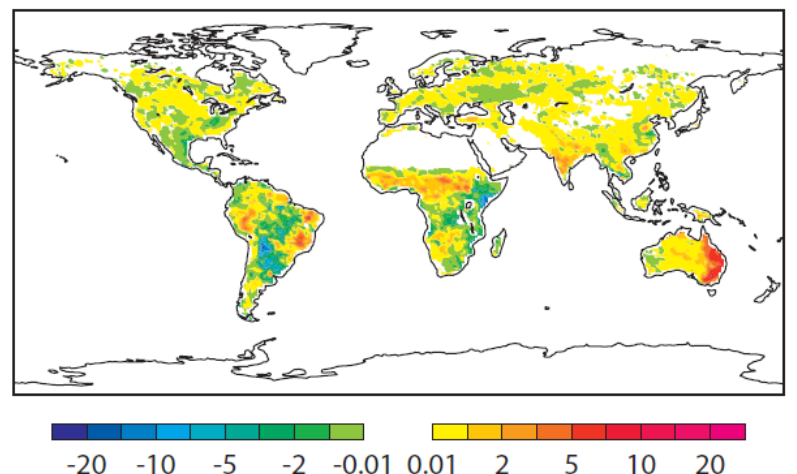

d)

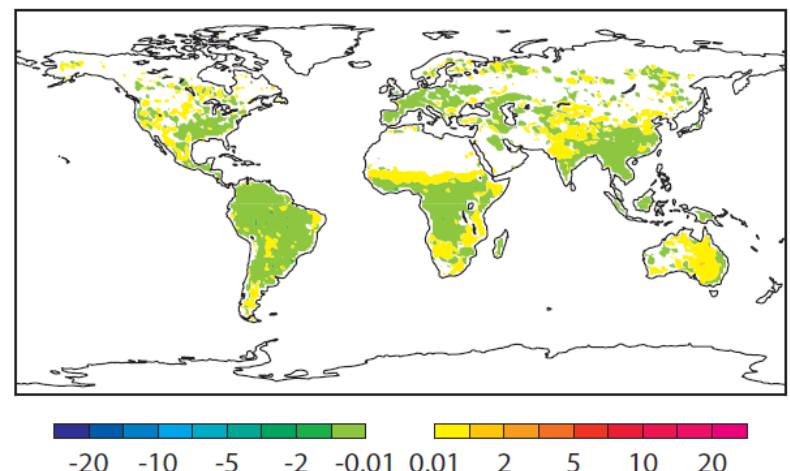

Figure 9: Similar to Figure 7 for the Latent Heat flux $\left[\mathrm{W} \mathrm{m}^{-2}\right]$.

a)

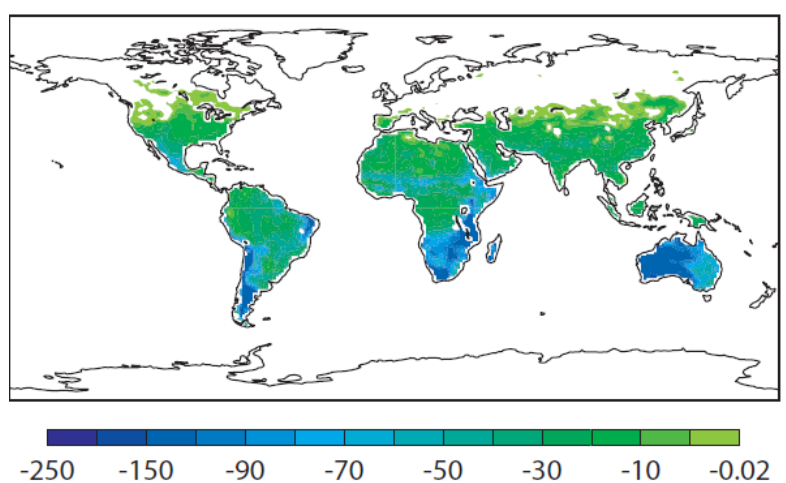

b)

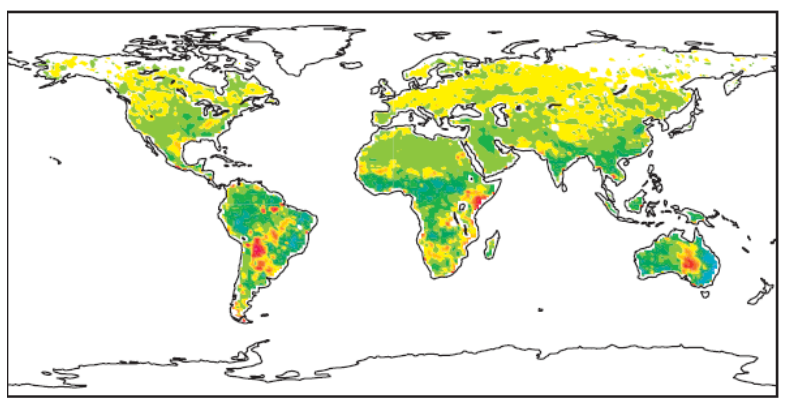

$\begin{array}{lllllllllllll} & & \mid & \mid & \mid & \mid & & & & \\ -20 & -10 & -5 & -2 & -0.01 & 0.01 & 2 & 5 & 10 & 20\end{array}$ c)

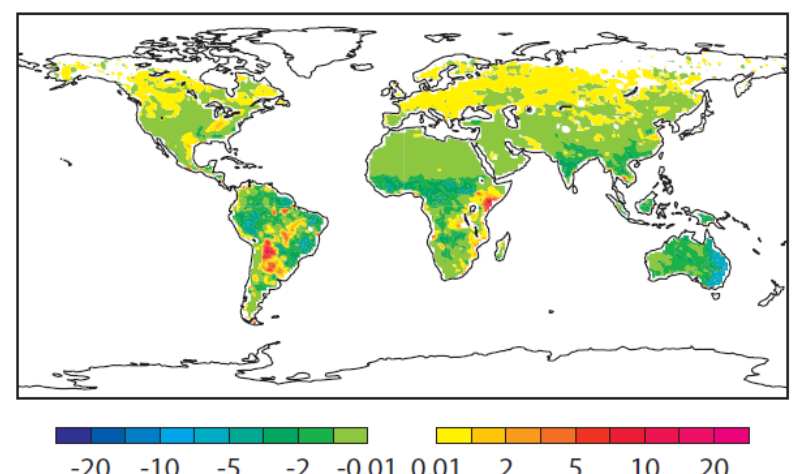

d)

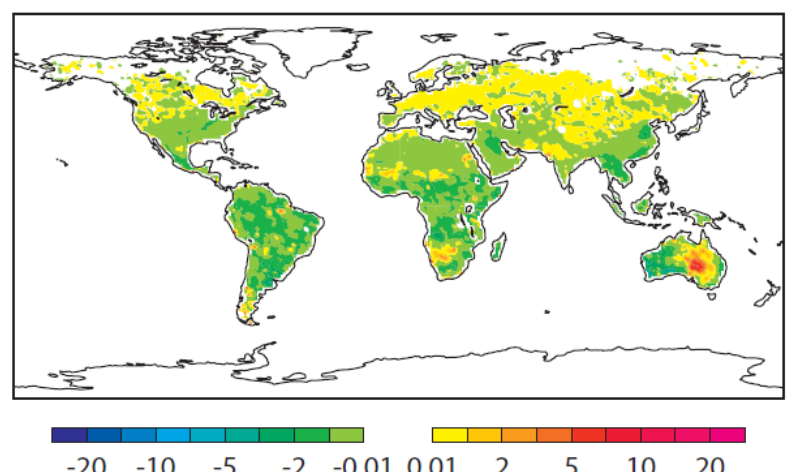

Figure 10: Similar to Figure 7 for the Sensible Heat flux $\left[\mathrm{W} \mathrm{m}^{-2}\right]$. 
a)

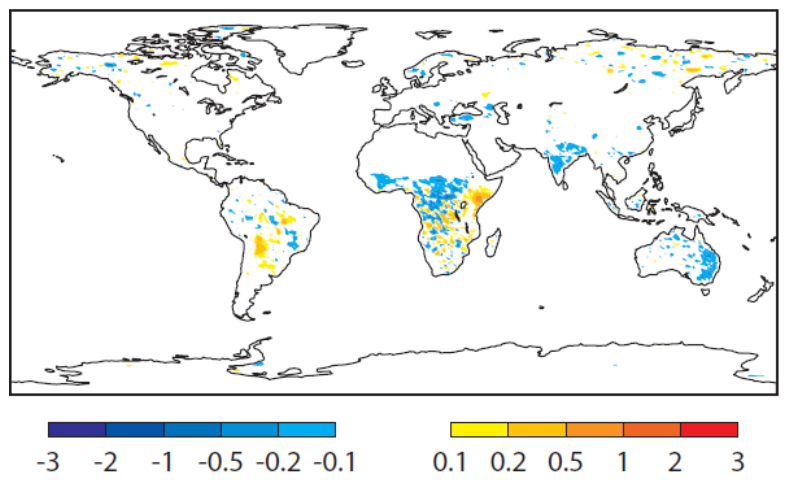

b)

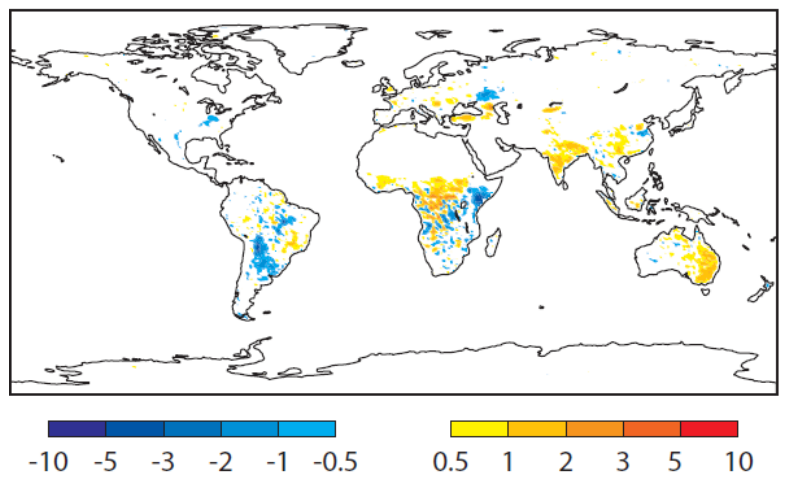

c)

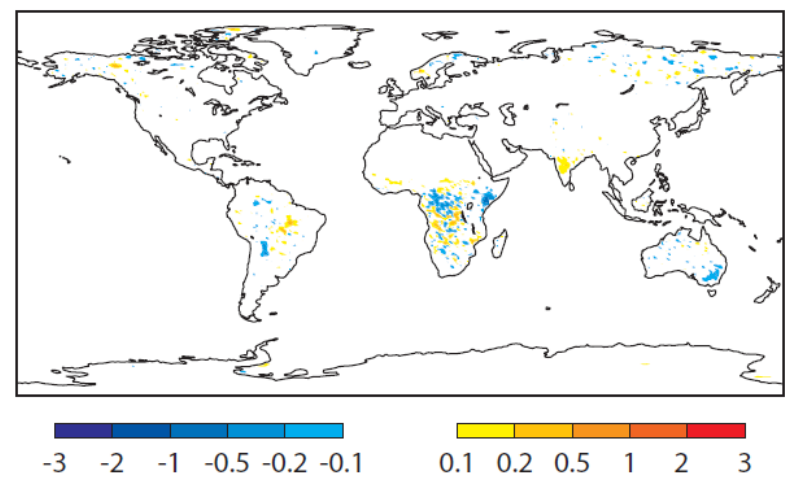

d)

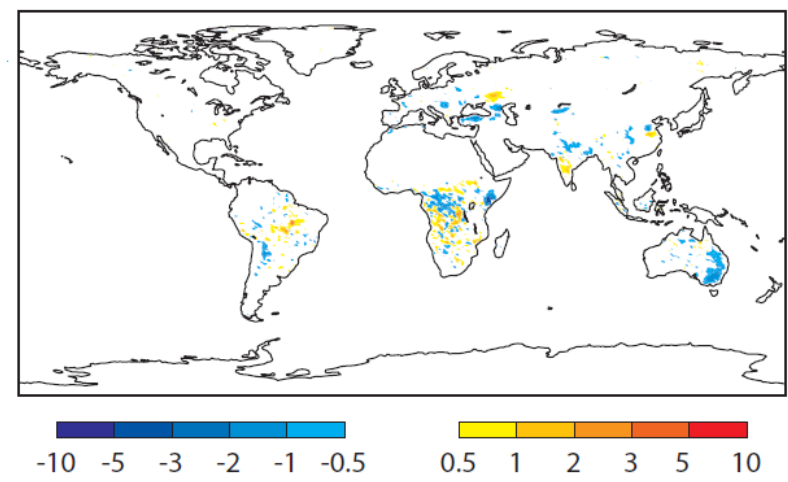

Figure 11: Scores of forecast experiment using LAI NRT (FLAINRT) against experiment using climatology (FCLIM) for November 2010: a) 2-m temperature sensitivity [K], b) 2-m relative humidity sensitivity [\%], c) 2-m temperature impact, and d) 2-m relative humidity impact. (A positive/negative value of the impact means an increase/reduction of the 2-m temperature/relative humidity error in comparison to the operational analysis). 
a)

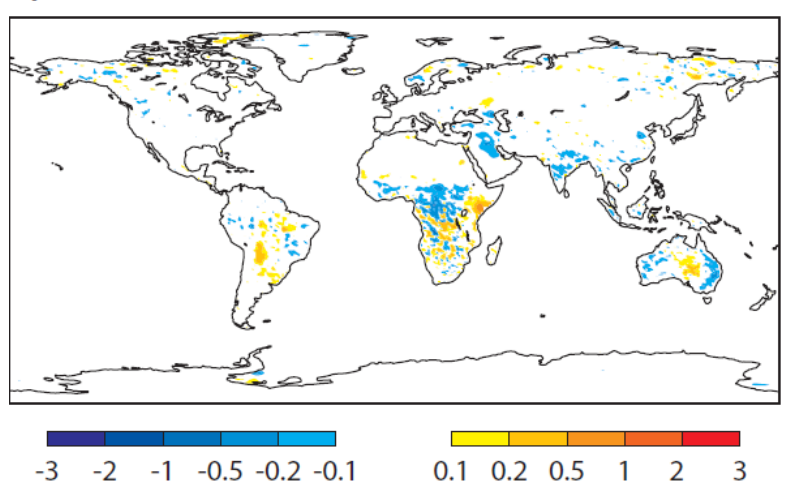

b)

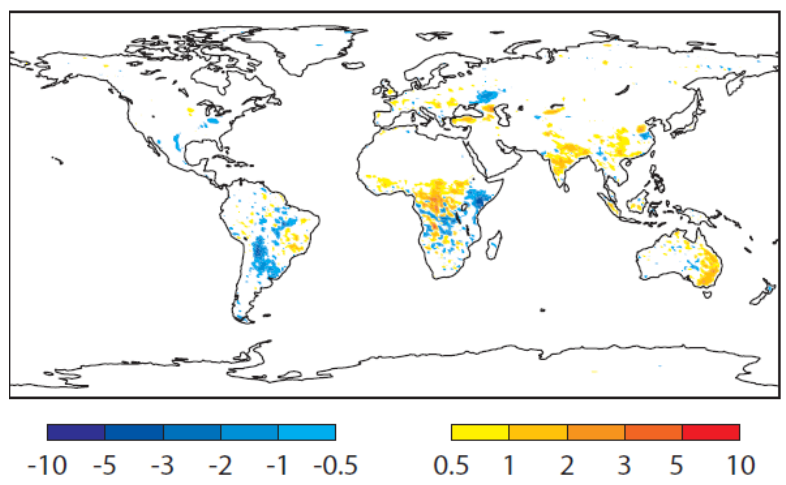

c)

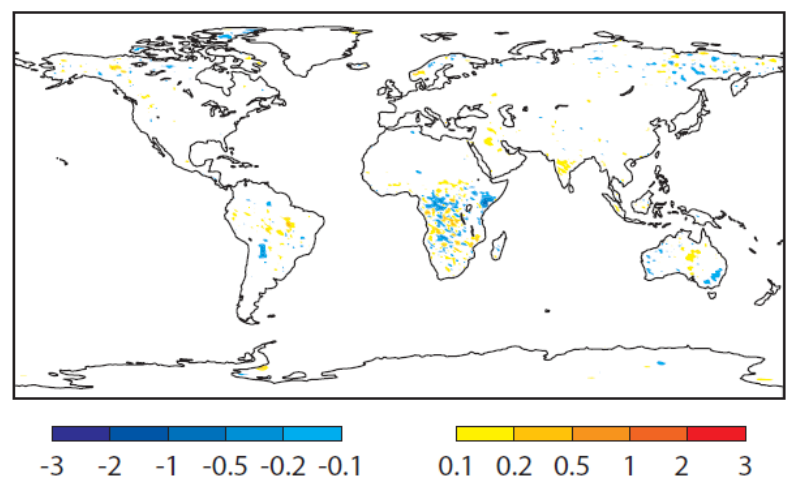

d)

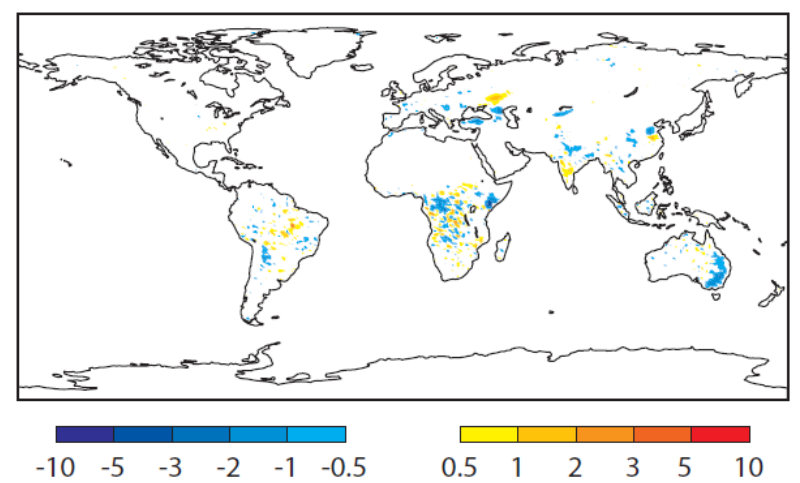

Figure 12: Scores of forecast experiment using LAI and albedo NRT (FNRT) against experiment using climatology (FCLIM) for November 2010: a) 2-m temperature sensitivity [K], b) 2-m relative humidity sensitivity [\%], c) 2-m temperature impact, and d) 2-m relative humidity impact. (A positive (negative) value of the impact means an increase (reduction) of the 2-m temperature/relative humidity error in comparison to the operational analysis). 
a)

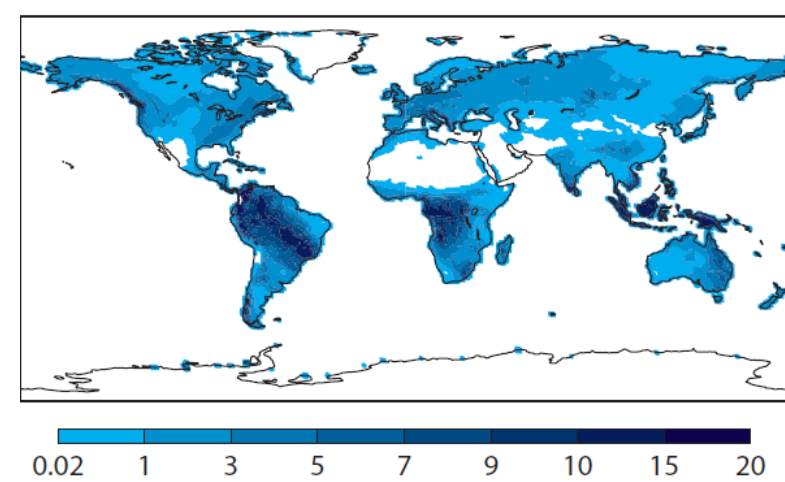

b)

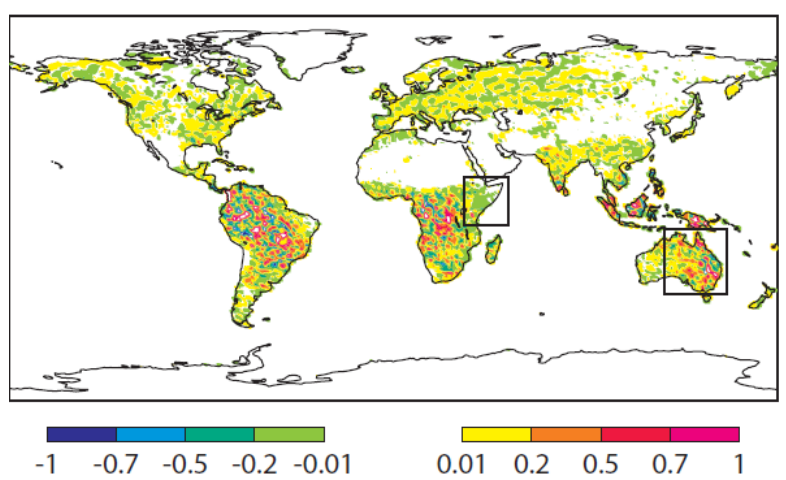

c)

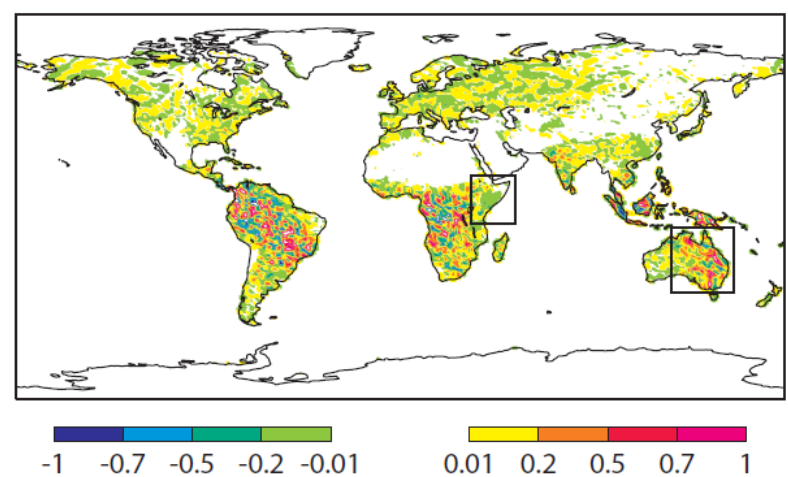

d)

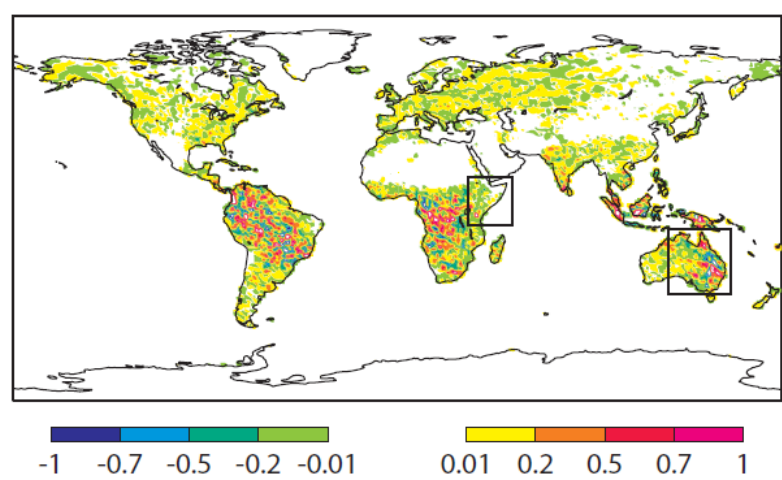

Figure 13: Forecast total precipitation [mm/day] for 48 to72 hour range using LAI and albedo climatology for November 2010 (a). Difference with simulation using LAI and albedo NRT analysis (FNRT-FCLIM) (b), difference with simulation using LAI NRT analysis (FLAINRT-FCLIM) (c), difference between simulation using LAI NRT analysis and simulation using both LAI and albedo NRT analysis (FNRT-FLAINRT) (d). Areas of interest are highlighted with the boxes. 
2 Table 1: Experiments configuration to assess the assimilation of NRT LAI and albedo impact.

\begin{tabular}{|l|l|l|l|l|l|}
\hline NAME & EXPERIMENT & LAI & Albedo & Surface initial & PERIOD \\
\hline SCLIM & Surface offline & Climatology & Climatology & ERA-Interim & $1999-2012$ \\
\hline SNRT & Surface offline & NRT & NRT & ERA--Interim & $1999-2012$ \\
\hline SLAINRT & Surface offline & NRT & Climatology & ERA-Interim & $1999-2012$ \\
\hline SALBNRT & Surface offline & Climatology & NRT & ERA-Interim & $1999-2012$ \\
\hline FCLIM & Forecast & Climatology & Climatology & SCLIM & 2010 \\
\hline FNRT & Forecast & FRT & NRT & SNRT & 2010 \\
\hline FLAINRT & Forecast & NRT & Climatology & SLAINRT & 2010 \\
\hline
\end{tabular}

3 
Table 2: Flux evaluation averaged against 52 FLUXNET sites for 2003: metrics based on 10-day averaged simulated fluxes. The confidence Interval (CI) of RMSE is based on the Chi-squared distribution and the 95\% CI of the mean correlation is based on the Fisher Z-transform.

\begin{tabular}{|c|c|c|c|c|c|c|c|c|c|}
\hline \multirow[t]{2}{*}{ Flux } & \multicolumn{3}{|c|}{ SCLIM } & \multicolumn{3}{|c|}{ SLAINRT } & \multicolumn{3}{|c|}{ SNRT } \\
\hline & RMSE & Bias & Corr. & RMSE & Bias & Corr. & RMSE & Bias & Corr. \\
\hline $\begin{array}{l}\text { Latent Heat }\left[\mathrm{W} / \mathrm{m}^{2}\right] \\
\mathrm{N} \text { sites better than } \\
\text { SCLIM }\end{array}$ & $\begin{array}{c}20.9 \\
( \pm 0.7) \\
-\end{array}$ & $\begin{array}{c}10.40 \\
-\end{array}$ & $\begin{array}{c}0.85 \\
( \pm 0.01) \\
-\end{array}$ & $\begin{array}{c}20.6 \\
( \pm 0.7) \\
34\end{array}$ & $\begin{array}{c}9.60 \\
36\end{array}$ & $\begin{array}{c}0.85 \\
( \pm 0.01) \\
\\
27\end{array}$ & $\begin{array}{c}20.6 \\
( \pm 0.7) \\
33\end{array}$ & $\begin{array}{c}9.63 \\
36\end{array}$ & $\begin{array}{c}0.85 \\
( \pm 0.01) \\
25\end{array}$ \\
\hline $\begin{array}{c}\text { Sensible Heat }\left[\mathrm{W} / \mathrm{m}^{2}\right] \\
\mathrm{N} \text { sites better than } \\
\text { SCLIM }\end{array}$ & $\begin{array}{c}20.3 \\
( \pm 0.7) \\
-\end{array}$ & $\begin{array}{c}-1.64 \\
-\end{array}$ & $\begin{array}{c}0.74 \\
( \pm 0.02) \\
-\end{array}$ & $\begin{array}{c}20.4 \\
( \pm 0.7) \\
\\
26\end{array}$ & $\begin{array}{r}-1.77 \\
39\end{array}$ & $\begin{array}{c}0.74 \\
( \pm 0.02) \\
\\
28\end{array}$ & $\begin{array}{c}20.5 \\
( \pm 0.7) \\
25\end{array}$ & $\begin{array}{c}-1.26 \\
35\end{array}$ & $\begin{array}{c}0.74 \\
( \pm 0.02) \\
29\end{array}$ \\
\hline $\begin{array}{c}\text { Gross Primary Prod. } \\
\left.\text { [ } \mu \text { mole } / \mathrm{m}^{2} / \mathrm{s}\right] \\
\mathrm{N} \text { sites better than } \\
\text { SCLIM }\end{array}$ & $\begin{array}{c}2.06 \\
( \pm 0.07)\end{array}$ & $\begin{array}{c}0.80 \\
-\end{array}$ & $\begin{array}{c}0.81 \\
( \pm 0.01)\end{array}$ & $\begin{array}{c}2.12 \\
( \pm 0.07) \\
25\end{array}$ & $\begin{array}{c}0.88 \\
18\end{array}$ & $\begin{array}{c}0.82 \\
( \pm 0.01) \\
33\end{array}$ & $\begin{array}{c}2.12 \\
( \pm 0.07) \\
25\end{array}$ & $\begin{array}{c}0.88 \\
18\end{array}$ & $\begin{array}{c}0.82 \\
( \pm 0.01) \\
31\end{array}$ \\
\hline
\end{tabular}

13 Table 3: Averaged metrics for surface and root-zone soil soil moisture benchmarking against the ISMN 14 sites for 2010 based on daily soil moisture values. The confidence Interval (CI) of RMSE is based on the 15 Chi-squared distribution and the $95 \%$ CI of the mean correlation is based on the Fisher Z-transform.

\begin{tabular}{|c|ccc|ccc|cc|}
\hline Soil moisture/Exp & \multicolumn{3}{|c|}{ SCLIM } & \multicolumn{3}{c|}{ SLAINRT } & \multicolumn{3}{c|}{ SNRT } \\
& RMSE & Bias & Corr. & RMSE & Bias & Corr. & RMSE & Bias \\
Corr.
\end{tabular}

